\title{
Quality Overprovision in Cable Television Markets
}

\author{
By Gregory S. Crawford, Oleksandr Shcherbakov, and Matthew Shum*
}

\begin{abstract}
We measure the welfare distortions from endogenous quality choice in imperfectly competitive markets. For US cable television markets between 1997-2006, prices are 33 percent to 74 percent higher and qualities 23 percent to 55 percent higher than socially optimal. Such quality overprovision contradicts classic results in the literature and our analysis shows that it results from the presence of competition from high-end satellite TV providers: without the competitive pressure from satellite companies, cable TV monopolists would instead engage in quality degradation. For welfare, quality overprovision implies cable customers would prefer smaller, lower-quality cable bundles at a lower price, amounting to a twofold increase in consumer surplus for the average consumer. (JEL L13, L15, L82)
\end{abstract}

Market power over price is one of the most widely understood and enduring concepts in economics. Whereas competitive markets, under standard assumptions, ensure the maximization of welfare, market power over price creates a wedge between the marginal social benefits and costs of production, introducing inefficiency in the form of deadweight loss. It is not surprising, then, that market power over price is the primary focus of antitrust and competition law and economics. ${ }^{1}$

There is much less focus on concerns about market power over quality, or over non-price attributes more generally. ${ }^{2}$ Just as they do with prices, firms in imperfectly competitive industries will distort quality levels away from socially optimal levels, but unlike prices, the direction of this distortion is not clear. Spence (1975)

\footnotetext{
* Crawford: Department of Economics, University of Zürich, Schönberggasse 1, 8001 Zürich, Switzerland (email: gregory.crawford@econ.uzh.ch); Shcherbakov: Currency Department, Bank of Canada, 234 Wellington Street, Ottawa, ON K1A 0G9, Canada (email: oshcherbakov@bank-banque-canada.ca); Shum: Caltech, HSS, Mailcode 228-77, Pasadena, CA 91125 (email: mshum@caltech.edu). Penny Goldberg was the coeditor for this article. We thank Dan Ackerberg, Gary Biglaiser, Eugenio Miravete, and seminar participants at Arizona, East Anglia, Harvard Business School, Helsinki, Northwestern, Mannheim, Maryland, UBC-Sauder, UCLA, Zürich, the 2016 Asia-Pacific IO Conference, the CEPR Conference on Competition in the New Economy, and the 2015 Zhejiang University IO conference for helpful comments. Crawford thanks ESRC Grant RES-062-23-2586 for financial support for this research. Special thanks goes to Chenghuan (Sean) Chu for providing the data used in this analysis and to Ali Yurukoglu, with whom we have had many fruitful discussions about cable television markets. The authors declare that they have no relevant or material financial interests that relate to the research described in this paper.

${ }^{\dagger}$ Go to https://doi.org/10.1257/aer.20151182 to visit the article page for additional materials and author disclosure statements.

${ }^{1}$ Examples include price-fixing, predatory pricing, and attempted monopolization, among others (Elhauge 2011). Similarly, the primary concern of merger review is exercise of market power over price due to unilateral or coordinated action (DOJ and FTC 2010).

${ }^{2}$ DOJ and FTC (2010, chapter 1) is a notable exception, stating, "Enhanced market power can also be manifested in non-price terms and conditions that adversely affect customers, including reduced product quality, reduced
} 
shows that a single-product monopolist may offer more or less quality than a social planner in the same market. There is a consensus view in the screening literature that cable monopolists degrade quality (Mussa and Rosen 1978, Maskin and Riley 1984). Despite this consensus, Champsaur and Rochet (1989) show that when consumers face high-end outside options, then the incentives may reverse, resulting in "quality overprovision" relative to the first best, making it an empirical question as to whether market power leads to over- or underprovision of quality in real-world settings.

In this paper, we measure the welfare effects of endogenous quality choice by US cable television systems. We estimate an equilibrium demand and supply model of consumers' choices across television bundles offered by cable and satellite TV companies. Based on the results, we compute how much offered qualities differ from those given by a welfare-maximizing social planner.

Importantly, we find that firms choosing both price and quality in the cable TV market tend to set both prices and quality too high relative to first-best socially optimal levels. This evidence for "quality overprovision" is novel compared to the classic results in the theoretical literature discussed above. Digging deeper to examine the sources of the quality overprovision result, we find that it is the presence of satellite TV competitors, who provide high-end substitutes for cable TV companies' offerings, which drive the quality overprovision result, rather than the rich consumer preference heterogeneity that we allow for in our demand model.

Our analysis builds on and extends previous empirical research looking at related questions. ${ }^{3}$ Berry and Waldfogel (2001) and Sweeting (2010) empirically analyze the effects of increased market power on product variety and/or quality, but do not optimally solve for those qualities. Clerides (2002) and Verboven (2002) analyze quality-based price discrimination, but focus primarily on documenting its presence. Where the types of products a firm can offer are discrete, the choice facing firms is whether to add any such product. In this vein, Draganska, Mazzeo, and Seim (2009); Eizenberg (2014); Nosko (2014); and Sweeting (2013) recover the fixed costs of offering new products and, in some cases, endogenously solve for new product introductions. Gandhi et al. (2008), Chu (2010), Fan (2013), and Byrne (2015) study firms' endogenous choices of continuous characteristics while holding the set of products fixed, as in this paper. Finally, we contribute to the literature analyzing economic issues in pay television markets (Goolsbee and Petrin 2004, Crawford and Yurukoglu 2012, Crawford et al. 2018).

The papers closest in spirit to ours are McManus (2007) and Crawford and Shum (2007). Both find evidence of quality degradation for low-quality products along the lines predicted by the theoretical literature above. Here, in contrast, using more flexible specification of preferences, we find evidence of quality overprovision, even for low-quality products, which is a novel finding in the empirical literature.

The empirical framework we propose is based closely on the empirical analysis of differentiated product markets pioneered by Berry (1994) and Berry, Levinsohn,

product variety, reduced service, or diminished innovation." They go on to say, "When the Agencies investigate whether a merger may lead to a substantial lessening of non-price competition, they employ an approach analogous to that used to evaluate price competition," but do not provide details.

${ }^{3}$ See Crawford (2012, Section 5) for more details about the related literature. 
and Pakes (1995). ${ }^{4}$ On the demand side, we specify a discrete-choice demand model with random coefficients on price and quality. We specify a total cost function which depends on both quantity and quality. Cable systems maximize profits by choosing optimally the price and quality of the products they choose to offer. ${ }^{5}$ Estimation is by generalized method of moments (GMM) using moments generated by demand and the first-order conditions for prices and qualities. Demand, marginal (quantity) cost, and marginal quality cost shifters serve as instruments. ${ }^{6}$

We estimate the model on a dataset of almost 12,000 cable system years between 1997 and 2006. We also incorporate annual data on prices and qualities for satellite competitors over the same period. US cable television markets during our sample period are well suited for our model for three reasons. First, the products that cable systems offer are bundles of television networks with higher-quality bundles uniformly including all of the networks in lower-quality bundles (and more). Limiting an empirical analysis to a single dimension of product quality is therefore reasonable in this setting. Second, there is interesting variation in the competition faced by systems in the sample. In the early part of our sample, cable television systems are largely local monopolies; while satellite competitors entered in the mid-1990s, regulations on their ability to import local broadcast networks before 2000 limited their ability to compete with incumbent cable systems. ${ }^{7}$ Finally, our data on cable (and satellite) markets are rich enough to accurately analyze endogenous quality. Cable systems in our data serve geographically distinct local cable markets. Within the sample, each offers at most three bundles of networks. For each offered bundle, we observe the price charged, its market share, and the television networks it offers. Following previous work in this literature (Chu 2010, Shcherbakov 2016), we use a weighted total number of television networks in a bundle as our measure of quality for that bundle, with weights for each channel given by the national average input costs paid by cable systems for that channel. ${ }^{8}$ We also observe (at the market level) variables that shift demand and costs across markets.

Based on our estimates of preferences and costs, we calculate consumer surplus, profit, and thus total surplus associated with observed prices and qualities. We then simulate counterfactual prices and qualities for a social planner offering the same number of products and maximizing total surplus in each market and compare the qualities offered in the market with those offered by a social planner.

Our results show that, compared to the social optimum, a profit-maximizing monopolist sets both price and quality too high: that is, the monopolist overpro-

\footnotetext{
${ }^{4}$ Applications using this framework are too numerous to count but include measuring the market power of firms (Nevo 2001), conducting simulations of potential mergers (Berry and Pakes 1993), testing for price discrimination (Verboven 2002), and quantifying the welfare benefits of new goods (Petrin 2002).

${ }^{5}$ The number of offered products depends on the technology used by cable systems and is therefore plausibly exogenous to annual price and quality decisions.

${ }^{6}$ Our framework also addresses the endogeneity of quality in the estimation of demand, an important econometric problem in its own right. Relatedly, see Ackerberg, Crawford, and Hahn (2011) for methods to consistently estimate (only) price elasticities in the presence of endogenous product characteristics, which can be multidimensional (unlike the case of scalar quality considered here).

${ }^{7}$ Furthermore, while cable system prices were regulated in 1992, the effects of these regulations were mitigated due to the nature of their implementation and were effectively withdrawn for the vast majority of cable bundles by 1996. See Crawford and Shum (2007) for more detail on the regulations and the effects they had on cable market quality.

${ }^{8}$ Thus, channels that are expensive to the cable system (ESPN, TNT, CNN, etc.) contribute more to the measured quality of a cable bundle than channels that are inexpensive to the system.
} 
vides quality. We estimate that a social planner would lower qualities by between 23 percent and 55 percent (and prices by between 33 percent and 74 percent). A wide range of robustness checks and additional simulations establish that this result is robust to changes in model parameters and specifications. While this evidence for quality overprovision by cable operators reverses previous theoretical and empirical results (Mussa and Rosen 1978, Crawford and Shum 2007) emphasizing that a monopolist distorts quality downward, it provides empirical confirmation of theoretical results from Champsaur and Rochet (1989), who show how a monopolist facing competition from a high-end outside option may optimally overprovide quality to its consumers. Indeed, additional results suggest that it is the presence of high-end satellite competition which drives the overprovision result; when we remove satellite competition, then the result essentially disappears.

In addition, the quality overprovision results implies that cable customers would prefer lower-quality (i.e., smaller) cable bundles at a lower price, and moving to this socially-optimal product line would generate, on average, a more-thantwofold increase in consumer surplus. Such a finding opens up an important new perspective for US policymakers concerned about high and rising pay television prices.

The rest of the paper proceeds as follows. In the next section, we describe the economic intuition underlying the measurement of market power over quality. In Section II, we describe the institutional features of US cable television markets that make estimating the model there attractive as well as the data we are using for our analysis. In Section III, we describe the equilibrium demand and supply framework underlying our empirical model. In Section IV, we elaborate on details of model specification, and discuss the identification of structural parameters and our choice of instrumental variables for estimation. Section V presents our estimation results, and also the results from counterfactual experiments which compare the observed prices and qualities to socially optimal values. Section VI delves into the robustness of and explanations for the quality overprovision result. Section VII concludes.

\section{Market Power over Quality}

In this section, we describe the economic intuition underlying market power over quality. Following Spence (1975), we begin with the simplest case where a single product monopolist chooses quality, $q$, and price, $P$, and each consumer buys one unit of the good. Let $P(s, q)$ denote the inverse demand function facing the monopolist, where $s$ denotes quantity, and let $C(s, q)=c(q) s$ be a constant returns to scale cost function. The monopolist's first-order conditions for quantity and quality controls are then

$$
\begin{aligned}
\text { F.O.C. }{ }^{M}[s]: & P(s, q)+P_{s}(s, q) s & =c(q), \\
\text { F.O.C. }{ }^{M}[q]: & P_{q}(s, q) & =c_{q}(q),
\end{aligned}
$$


where $P_{q}(s, q)$ is Spence's "marginal valuation of quality" (MVQ) for the $s$ th consumer. 9

A social planner maximizes total surplus

$$
\max _{s, q}\left\{\int_{0}^{s} P\left(s^{\prime}, q\right) d s^{\prime}-c(q) s\right\}
$$

yielding first-order conditions (FOC) for quantity and quality that equate the marginal social benefit of each with their marginal cost, 10

$$
\begin{aligned}
\text { F.O.C. }{ }^{S P}[s]: & P(s, q) & =c(q), \\
\text { F.O.C. }{ }^{S P}[q]: & \frac{1}{s} \int_{0}^{s} P_{q}\left(s^{\prime}, q\right) d s^{\prime} & =c_{q}(q) .
\end{aligned}
$$

While the difference between (1) and (3) is familiar as a manifestation of market power over price, the difference between (2) and (4) shows that profit maximizing and socially optimal quality levels are also likely to be different. While the monopolist equates the marginal quality $\operatorname{cost}, c_{q}(q)$, to the marginal value of quality for the marginal $(s t h)$ consumer, $P_{q}(s, q)$, the social planner equates it to the marginal value of quality to the marginal value of quality, averaged across all consumers, $\frac{1}{s} \int_{0}^{s} P_{q}\left(s^{\prime}, q\right) d s^{\prime}$

In our empirical model below, preference heterogeneity is multidimensional, depending on the distribution of random coefficients and utility shocks which vary across households as well as across product offerings. In this more complex, but arguably more realistic setup, we cannot define "marginal" or "inframarginal" consumers. Nevertheless, Spence's main insight remains, that market power can lead to either over- or underprovision of quality (relative to the social planner) depending on households' preferences.

Models of multi-product monopoly quality choice typically apply principal-agent models of adverse selection like those used in the analysis of optimal nonlinear pricing. Seminal papers in this area include Mussa and Rosen (1978) and Maskin and Riley (1984). Under standard assumptions, a common set of results emerge: (i) quality to the highest type is set efficiently (i.e., there are no "Spence-ian" distortions at the top of the type distribution), (ii) qualities to lower types are degraded downward, (iii) prices are set such that the lowest type receives no surplus, and (iv) higher types earn positive surplus (information rents).

However, an important restriction in this model is that the consumers' main alternative to the monopolist's offerings are a low-quality outside option; this drives the quality degradation result as the monopolist will optimally engage in quality degradation to low-valuation consumers in order to extract more surplus from high-valuation consumers. It turns out that this result depends crucially on the location of the outside option on the quality spectrum; indeed, Champsaur and Rochet (1989, Section 3) show that, if one were to make the outside option a high-end alternative, then the

\footnotetext{
${ }^{9}$ If $P(s, q)$ measures the willingness-to-pay (WTP) of the sth consumer, then $P_{q}(s, q)$ measures how much her WTP increases with increases in quality.

${ }^{10}$ Equation (4) assumes that differentiation under the integral sign is possible, which is satisfied for the parametric demand specifications considered in this paper, which are continuously differentiable.
} 
result can reverse; that is, the monopolist may overprovide quality in order to optimally extract surplus from its consumers. This may be a relevant scenario for cable television markets, as an important alternative to the cable companies' offerings are those of direct-broadcast satellite (DBS) providers, who offer more extensive (larger) and (often) more expensive bundles relative to cable TV bundles.

As this summary of the theory has highlighted, market power can lead to either quality over- or underprovision, depending on features of consumer heterogeneity and preferences, as well as market structure and competition. Ultimately, then, the direction of cable monopolists' quality distortions is an empirical question, which we focus on in what follows.

\section{Data and Institutional Details}

Cable television, formerly known as Community Antenna Television (CATV), emerged in the late 1940s in Arkansas, Oregon, and Pennsylvania to deliver broadcast signals to the remote areas with poor over-the-air reception. ${ }^{11}$ In these areas, homes were connected to the antenna towers located at the high points via cable networks. Starting with 70 cable systems serving about 14,000 subscribers in 1952, a decade later almost 800 cable systems served about 850,000 subscribers. By October 1998, the number of cable systems reached 10,700 , providing service to more than 65 million subscribers in 32,000 communities (FCC 2000).

Specifically, cable television systems select a portfolio of programming networks, bundle them into one or more services and offer these services to households in local, geographically separate, cable markets. Systems typically offer three types of networks: broadcast networks, cable networks, and premium networks. ${ }^{12}$

Broadcast and cable networks are typically bundled by cable systems and offered as Basic Service. Some systems, however, elect to split up these networks and offer a subset of them as Expanded Basic Services. Starting in the late 1990s, cable systems invested in digital technologies, allowing them to offer more television signals on a given infrastructure. At this time, they often introduced additional bundles of networks called Digital Basic Services. Expanded and Digital Basic Services were only available to households who had purchased the Basic Service bundle.

The institutional and economic environment in the cable television industry suggests the choice of quality and price of Basic, Expanded Basic, and Digital Basic Services may map well to the theory. Since households that buy Expanded and Digital Basic Services must necessarily first purchase Basic Service, these services are by construction increasing in overall quality. Furthermore, since they consist of (generally large) bundles of individual networks, the range of qualities possibly chosen is plausibly continuous, and offered qualities are clearly discrete. ${ }^{13}$

\footnotetext{
${ }^{11}$ See National Cable and Telecommunications Association (NCTA), http://www.ncta.com/About/About/ HistoryofCableTelevision.aspx (accessed March 1, 2009).

${ }^{12}$ Broadcast networks are television signals broadcast in the local cable market and then collected and retransmitted by cable systems. Examples include the major national broadcast networks (ABC, CBS, NBC, and FOX) as well as public and independent television stations. Cable networks are advertising-supported general and special-interest networks distributed nationally to systems via satellite, such as MTV, CNN, and ESPN. Premium networks are advertising-free entertainment networks, typically offering full-length feature films, such as HBO and Showtime.

${ }^{13}$ In a complementary line of analysis, Crawford (2008) and Crawford and Yurukoglu (2012) consider the incentives to bundle networks into Basic Services. This line of work tests the discriminatory incentives to
} 
Table 1-DBS Penetration Rates in 2001-2004 (Percentages)

\begin{tabular}{lccc}
\hline \hline & 2001 & 2004 & Change \\
\hline Rural & 26 & 29 & 12 \\
Suburban & 14 & 18 & 29 \\
Urban & 9 & 13 & 44 \\
\hline
\end{tabular}

Source: Government Accountability Office report to the US Senate, April 2005

An important feature of cable system management is their almost complete control over the content (quality) and price of their bundles. While certain regulations mandate systems carry all broadcast television stations available over the air in their service area (so-called "must-carry" requirements), beyond these restrictions they may select and package whatever television networks they like for sale to households. ${ }^{14}$ With respect to prices, cable systems have been subject to cyclical regulatory oversight. 15 Most recently, the 1996 Telecommunications Act removed price controls on Expanded and Digital Basic Services, leaving only Basic Service subject to possible, though extremely weak regulation.

Until the 1990s, local cable systems were effectively natural monopolies as they faced virtually no competition except in a few cases of "overbuilt" systems where the same location was served by more than one cable company. Direct broadcast satellite (DBS) service was launched in the early 90s and originally was popular mostly in rural areas where cable service did not exist. Since then the number of subscribers of DBS providers has experienced rapid growth, as shown in Table 1.

DBS and cable operators use different quality and price setting strategies. While satellite operators set prices and products uniformly at the national level, cable systems make pricing and programming decisions locally. We model this difference by assuming that the evolution of satellite product and price options changes exogenously over time and that cable televisions systems respond strategically to these changes. In each local market, cable television systems are still therefore monopolists, but face a residual demand curve which depends on the presence and product choices of satellite TV operators. 16

We have compiled a market-level dataset on a cross section of United States cable systems to estimate the model. The primary source of data for these systems is Warren Publishing's Television and Cable Factbook Directory of Cable Systems. The data for this paper consist of the population of cable systems recorded in the

bundle: namely that by reducing heterogeneity in consumer tastes, bundling implicitly sorts consumers in a manner similar to second-degree price discrimination.

${ }^{14}$ Must-carry requirement do not appear to be a binding constraint on the firms' bundle choices, as the proportion of free of charge networks included in cable firms' bundles (an upper bound on the fraction of must-carry channels) is typically quite small.

${ }^{15}$ The most recent incident of price regulation was the 1992 Cable Act, the intent of which was to limit the prices charged for Basic and Expanded Basic Services. Due to a combination of factors, including strategic responses by cable systems to the imposed regulations and relatively weak cost pass-through (going-forward) requirements, these provided little benefit to households (Hazlett and Spitzer 1997, Crawford 2000).

${ }^{16}$ This accurately characterizes the pay television market in the sample period (1997-2006). During these years, DBS companies (Dish and DirecTV) set their products and prices at a nationwide level, whereas individual cable systems were permitted significant discretion in setting their channel lineups and prices to match local demand conditions, even when they were part of a larger Multiple System Operator (MSO, e.g., Comcast or Time Warner). In such a market context, even if DBS companies were to respond to cable firms, they would do so at a national level, and such a response would be diffused and of second-order importance for local-market outcomes. 
1997-2006 editions of the Factbook for which complete information was available. ${ }^{17}$ From the population, a sample of 3,931 systems remained. An observation in the data is a cable system-year.

Table 2 presents sample statistics for selected variable for these systems. Cable systems varied in the number of years they were in the sample, ranging from one to nine years, implying an unbalanced panel. Sample cable systems offer between one and three bundles, while satellite systems offer between three and six (with exactly three from 2002). ${ }^{18}$ We measure the quality of a bundle by the weighted average of the number of television networks offered on that bundle. The weights are given by the national average input cost (affiliate fee) paid by cable systems for that network, which is the carriage cost negotiated between that network and cable systems, averaged across all cable systems nationwide. This follows earlier empirical work by Chu (2010) and Shcherbakov (2016). As expected, prices and qualities are increasing across product tiers. ${ }^{19}$ Moreover, we see that at every tier (low, medium, or high), the measured quality of satellite bundles exceeds that of cable bundles, which can be interpreted to imply that in these markets, satellite products provide a high-end alternative to cable products. This observation will play an important role in what follows.

Figure 1 presents histograms for aggregate cable and satellite market shares as well as for product-specific cable market shares.

\section{A. Preliminary Evidence of Quality Over-/Underprovision}

The theory literature beginning with Mussa and Rosen (1978) connects market power with quality degradation for low-quality products offered by multi-product firms, and Crawford and Shum (2007) investigated whether indeed prices-per-channel in cable markets were higher for low-quality cable services. In Table 3, we present some exploratory evidence of quality degradation along the lines of Crawford and Shum (2007), using both their measure of product quality, price-per-channel, as well as the measure of product quality for which we advocate above, price-per-weighted-channel, with weights given by the national average input fee for each channel.

The evidence is largely inconclusive. While there is some evidence of higher prices-per-channel for lower-quality cable services, the significant heterogeneity in the raw underlying data prevents the differences from being statistically significant.

Going one step further, Champsaur and Rochet's (1989) model shows that a monopolist may engage in quality overprovision, when it faces competition from

\footnotetext{
${ }^{17}$ While there are over 11,000 systems per year in the sample, persistence in non-response over time as well as incomplete reporting of critical variables required imposing a large number of conditions in order for a system to be included in each sample. Missing information on prices, quantities, and reporting dates were responsible for the majority of the exclusions.

${ }^{18}$ Satellite market shares are only available at a much wider level of aggregation than cable shares. Satellite data are reported for each of 210 Nielsen Designated Market Areas (DMA), each of which typically contain many local cable system markets. Following Chu (2007), in order to compute satellite market share in each cable market, we assume that within a DMA satellite subscribers constitute a constant proportion of the non-cable subscribers.

${ }^{19}$ Prices for cable and satellite services were adjusted by Consumer Price Index (CPI) with 1997 as the base year.
} 
Table 2-Data Summary Statistics, 1997-2006

\begin{tabular}{|c|c|c|c|c|}
\hline & Mean & $\mathrm{SD}$ & Min & Max \\
\hline \multicolumn{5}{|l|}{ Periods and products } \\
\hline Time periods, years & 2.1 & 1.2 & 1 & 9 \\
\hline Cable products & 1.5 & 0.7 & 1 & 3 \\
\hline Satellite products & 5.2 & 1.4 & 3 & 6 \\
\hline \multicolumn{5}{|l|}{ Market shares } \\
\hline$s^{c}$ & 0.54 & 0.19 & 0.05 & 0.90 \\
\hline$s^{s}$ & 0.15 & 0.12 & 0.01 & 0.88 \\
\hline \multicolumn{5}{|l|}{ Prices } \\
\hline \multicolumn{5}{|l|}{ Cable } \\
\hline$p_{\text {Low }}^{c}$ & $\$ 20.44$ & $\$ 7.71$ & $\$ 2.68$ & $\$ 81.86$ \\
\hline$p_{M e d}^{c}$ & $\$ 32.77$ & $\$ 14.59$ & $\$ 7.88$ & $\$ 136.30$ \\
\hline$p_{\text {High }}^{c}$ & $\$ 60.28$ & $\$ 23.79$ & $\$ 16.90$ & $\$ 291.08$ \\
\hline \multicolumn{5}{|l|}{ Satellite } \\
\hline$p_{\text {Low }}^{s}$ & $\$ 21.69$ & $\$ 9.33$ & $\$ 14.44$ & $\$ 39.24$ \\
\hline$p_{M e d}^{s}$ & $\$ 27.15$ & $\$ 9.06$ & $\$ 19.26$ & $\$ 43.61$ \\
\hline$p_{\text {High }}^{s e d}$ & $\$ 45.95$ & $\$ 22.94$ & $\$ 28.89$ & $\$ 87.22$ \\
\hline \multicolumn{5}{|l|}{ Quality } \\
\hline \multicolumn{5}{|l|}{ Cable } \\
\hline$q_{\text {Low }}^{c}$ & 3.09 & 1.81 & 0.30 & 13.13 \\
\hline$q_{M e d}^{c}$ & 5.76 & 2.63 & 0.71 & 16.86 \\
\hline$q_{H i g h}^{c}$ & 9.11 & 3.45 & 2.34 & 19.02 \\
\hline \multicolumn{5}{|l|}{ Satellite } \\
\hline$q_{\text {Low }}^{S}$ & 5.12 & 3.49 & 1.78 & 11.73 \\
\hline$q_{\text {Med }}^{s}$ & 6.48 & 3.16 & 3.30 & 12.67 \\
\hline$q_{\text {High }}^{s}$ & 10.77 & 6.51 & 5.65 & 27.88 \\
\hline \multicolumn{5}{|l|}{ Other variables } \\
\hline Length of cable network, miles & 0.160 & 0.560 & 0.000 & 17.690 \\
\hline Channel capacity & 44.9 & 20.2 & 5 & 542 \\
\hline \multicolumn{5}{|l|}{ Before 2002} \\
\hline$p_{\text {Tier } 3}^{s}$ & $\$ 35.98$ & $\$ 4.26$ & $\$ 32.75$ & $\$ 43.80$ \\
\hline$p_{\text {Tier } 4}^{s}$ & $\$ 41.10$ & $\$ 2.92$ & $\$ 38.53$ & $\$ 46.59$ \\
\hline $\begin{array}{l}P \text { Tier } 4 \\
p_{\text {Tier } 5}^{s}\end{array}$ & $\$ 54.67$ & $\$ 12.65$ & $\$ 46.23$ & $\$ 77.35$ \\
\hline$q_{\text {Tier } 3}^{s}$ & 7.42 & 1.78 & 5.93 & 10.44 \\
\hline$q_{\text {Tier } 4}^{s}$ & 8.01 & 1.75 & 6.53 & 10.96 \\
\hline$q_{\text {Tier } 5}^{\text {siler }}$ & 9.45 & 3.49 & 6.96 & 15.44 \\
\hline
\end{tabular}

Notes: This table reports summary statistics for our estimation sample. Cable information is drawn from Warren Publishing's Television and Cable Factbook; satellite information was collected by hand. There are as many as six satellite products until 2001 and only three afterward. Market shares reported in the table are aggregated across all products offered on each platform (cable, satellite). Prices are in 1997 dollars. Low (or the only one if 1 product), Medium (second highest across having 2+ products), and High (third among 3-product markets) quality or price products are indexed by $\{0,1,2\}$ in the modeling section. The quality of a product is the weighted average of the number of television networks offered on that product, with weights given by the national average input cost (affiliate fee) paid by cable systems for that network from SNL Kagan. Length of cable network measures the size of the physical cable network, while channel capacity measures the maximum number of channels a given cable system can broadcast using its current physical network and compression technology. These data are augmented with market-level data on demographics from 2000 US Census.

a high-end substitute. We look for reduced-form evidence of this by analyzing variation in the presence of the high-end (satellite) outside option across markets; specifically, variation in when DBS begin carrying local channels and, thus, become a true "high-end" substitute for cable services. These data are available for about 6,610 markets (54 percent of total number of markets). Table 4 summarizes the 

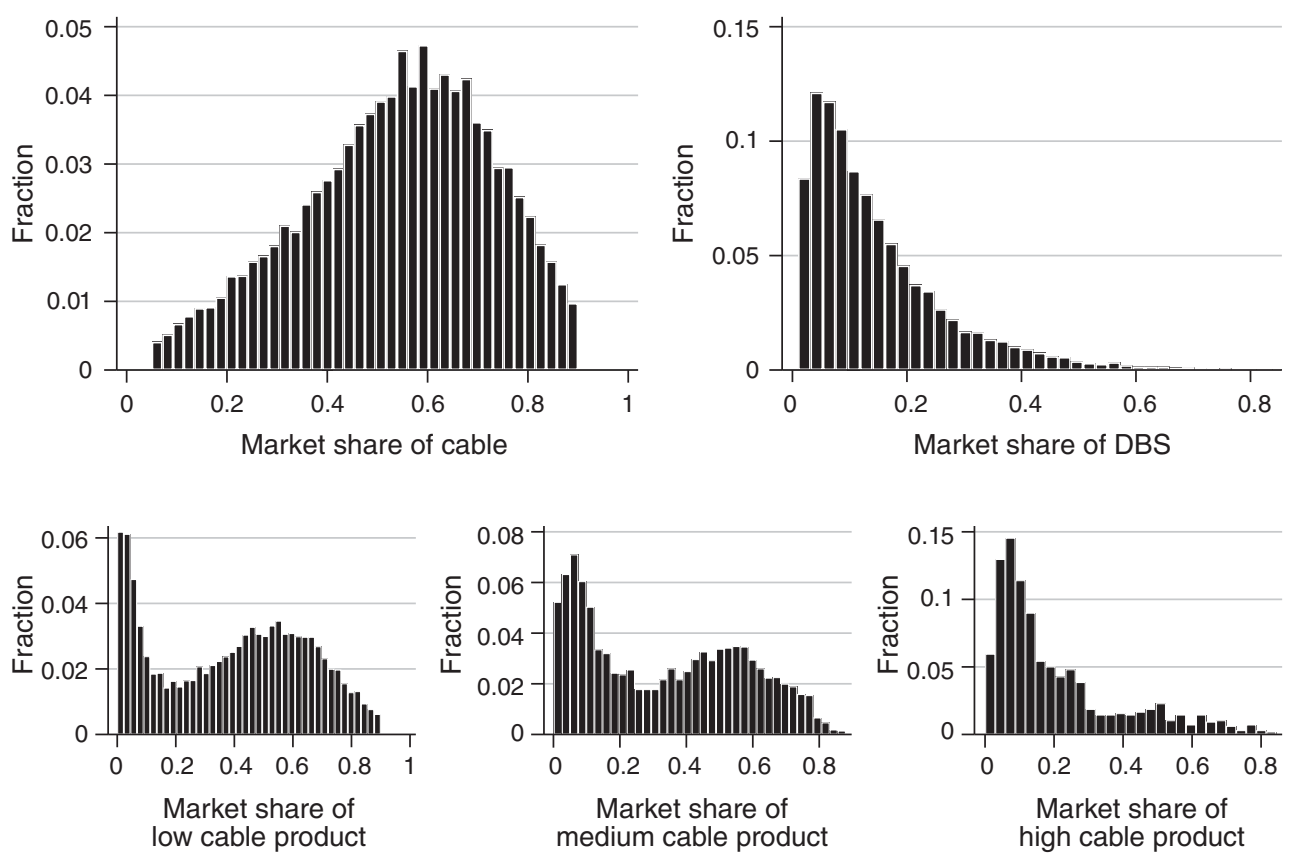

Figure 1. Histograms for Cable and Satellite Market Shares

results of this exercise. ${ }^{20}$ Across all markets and product tiers, we see evidence of higher quality when DBS offers local channels. ${ }^{21}$

As with any reduced-form analysis, there are a number of confounding factors. The launch date for local channels could be endogenous as regulations allowing DBS to carry local channels were first allowed in November 1999 (also known as the Satellite Home Viewer Improvement Act). If cable firms anticipate DBS launching local channels in the future, they may act preemptively. On the other hand, DBS may choose to launch local channels in markets that would experience high growth rates in the future. ${ }^{22}$ In this case, profitable developments in the market may affect both the decision of DBS to introduce local channels earlier and the decision of cable firms to improve product quality.

While suggestive, the reduced-form evidence here is uninformative as to how much a monopolist distorts quality and prices from their efficient levels. In order to quantify this, we specify and estimate a structural model of demand, pricing, and quality choice in cable television markets, which we introduce in the next section.

\section{Model}

Consider a market, $n$, served by two providers of paid television service: cable and satellite, denoted with $g \in\{c, s\}$, each offering multiple products indexed by

\footnotetext{
${ }^{20}$ Differences for each year are available upon request.

${ }^{21}$ In Appendix A, we present supplementary regression results which show that cable firms choose higher levels of quality in years close to the satellite competitor's decision to carry local channels.

${ }^{22}$ In our data we cannot see this because our demographics are fixed at their values in year 2000.
} 
Table 3-Exploratory Evidence of Quality Degradation

\begin{tabular}{|c|c|c|c|c|}
\hline & \multicolumn{2}{|c|}{ Three-good markets } & \multicolumn{2}{|c|}{ Two-good markets } \\
\hline & Mean & Difference & Mean & Difference \\
\hline \multicolumn{5}{|c|}{ Prices-per-channel } \\
\hline$p_{c 2} /$ channel $s_{2}$ & $1.28(0.64)$ & $0.46(0.34)$ & $1.38(0.82)$ & $-0.31(1.50)$ \\
\hline$p_{c 1} /$ channel $s_{1}$ & $0.81(0.40)$ & $-0.42(0.87)$ & $1.69(1.50)$ & \\
\hline$p_{c 0} /$ channel $s_{0}$ & $1.23(1.04)$ & & & \\
\hline \multicolumn{5}{|c|}{ Prices-per-weighted-channel } \\
\hline$p_{c 2} / q_{c 2}$ & $7.27(2.74)$ & $2.03(1.74)$ & $6.60(2.39)$ & $-4.26(10.02)$ \\
\hline$p_{c 1} / q_{c 1}$ & $5.24(2.21)$ & $-5.11(7.52)$ & $10.86(10.20)$ & \\
\hline$p_{c 0} / q_{c 0}$ & $10.34(8.21)$ & & & \\
\hline Observations & \multicolumn{2}{|c|}{1,360} & \multicolumn{2}{|c|}{3,727} \\
\hline
\end{tabular}

Notes: Reported are the average price per channel and price per weighted channel for each ordered cable service in our estimation sample. Weights are given by the national average input cost for that channel in the relevant year. Values in the Difference columns are the difference in price per channel in that row and the row that follows. Standard errors are in parentheses.

Table 4-Cable Quality Choice and DBS Carriage of Local Channels

\begin{tabular}{lccc}
\hline \hline Variable & $\begin{array}{c}\text { DBS carriage } \\
\text { of local channels }\end{array}$ & $\begin{array}{c}\text { No DBS carriage } \\
\text { of local channels }\end{array}$ & Difference \\
\hline 1-product, $q_{c 0}$ & 4.09 & 3.87 & 0.22 \\
2-product, $q_{c 0}$ & 4.51 & 3.97 & 0.54 \\
2-product, $q_{c 1}$ & 6.38 & 5.94 & 0.44 \\
3-product, $q_{c 0}$ & & & \\
3-product, $q_{c 1}$ & 3.01 & 2.44 & 0.57 \\
3-product, $q_{c 2}$ & 8.95 & 7.92 & 1.03 \\
\hline
\end{tabular}

$j \in \mathcal{J}_{g n}$. Our model is static and, for simplicity, we omit time subscripts such that $n$ denotes both market and time. One can characterize a multi-product cable carrier offering $J_{c n}$ distinct products by their monthly subscription fees, $p_{c j n}$, and quality of programming content, $q_{c j n}$, which we assume can be summarized by a scalar.

\section{A. Demand}

There are a continuum of consumers, indexed by $i$, whose preferences for a product $j$ offered by a provider $g$ depend on the monthly subscription fee, $p_{j g n}$, and service quality, $q_{j g n}$, of that product. Let $i$ 's indirect utility function be given by

(5) $U_{i j g n}$

$$
=\left\{\begin{array}{ll}
\delta_{g j n}\left(p_{g j n}, q_{g j n}, \bar{Y}_{i n}, \xi_{g n} ; \omega_{i}\right)+\epsilon_{i g n} & \text { for product } j \text { of provider } g \text { in market } n \\
\epsilon_{i 0 n} & \text { otherwise }
\end{array},\right.
$$


where $\omega_{i}$ denotes consumer $i$ 's heterogeneous preferences. 23 These are assumed to be known to consumer $i$, but unobserved by the econometrician. The term $\xi_{g n}$ denotes unobserved characteristics of provider $g$ in market $n$, and $\bar{Y}_{i n}$ is a vector of observable demand shifters (e.g., consumer demographics). Both the unobserved characteristics, $\xi_{g n}$, and the idiosyncratic preference draw, $\epsilon_{i g n}$, are provider-specific and not product-specific (i.e., both depend on $g$ instead of $j$ ). There are several reasons for these assumptions. First, they are consistent with the institutional features of the industry, where higher-quality products always include all programming content carried on low-quality products. The second reason is data-driven. For a large number of markets, we do not observe product-specific cable market shares, e.g., these data are missing for 15 percent of observations in 2-product markets and 35 percent of observations in 3-product markets. Therefore, allowing for product-specific unobservables would reduce our sample considerably. (We never observe satellite product-specific market shares and, therefore, cannot model product-specific unobservables for the DBS alternative.) We assume $\epsilon_{i g n}$ is distributed as Type I Extreme Value.

Total Provider Shares.-Let $\bar{p}_{g n}$ and $\bar{q}_{g n}$ denote observable vectors of prices and quality levels for all products offered by provider $g \in\{c, s\}$ in market $n$ and let the maximum utility a consumer type $i$ achieves by choosing among the products offered by provider $g$ be given by

$$
\delta_{g n}\left(\bar{p}_{g n}, \bar{q}_{g n}, \bar{Y}_{i n}, \xi_{g} ; \omega_{i}\right)=\max _{j^{\prime} \in \mathcal{J}_{g n}}\left\{\delta_{g j^{\prime} n}\left(p_{g j^{\prime} n}, q_{g j^{\prime} n}, \bar{Y}_{i n}, \xi_{g n} ; \omega_{i}\right)\right\} .
$$

Because $\epsilon_{i g n}$ is common to all the indirect utilities, $U_{i g j^{\prime} n}, \forall j^{\prime} \in \mathcal{J}_{g n}$, it doesn't influence the choice of product within provider for consumer type $i$.

The probability that a consumer of type $i$ chooses $g$ in $n$ is given by

$$
P_{g n}\left(\omega_{i}\right)=\frac{\exp \left(\delta_{g n}\left(\bar{p}_{g n}, \bar{q}_{g n}, \bar{Y}_{i n}, \xi_{g n} ; \omega_{i}\right)\right)}{1+\exp \left(\delta_{c n}\left(\bar{p}_{c n}, \bar{q}_{c n}, \bar{Y}_{i n}, \xi_{c n} ; \omega_{i}\right)\right)+\exp \left(\delta_{s n}\left(\bar{p}_{s n}, \bar{q}_{s n}, \bar{Y}_{i n}, \xi_{s n} ; \omega_{i}\right)\right)},
$$

and the aggregate market share of $g$ in $n$ is obtained by integrating over the distribution of consumer heterogeneity, $d F\left(\omega_{i}\right)$ :

$$
s_{g n}=\int \frac{\exp \left(\delta_{g n}\left(\bar{p}_{g n}, \bar{q}_{g n}, \bar{Y}_{i n}, \xi_{g n} ; \omega_{i}\right)\right)}{1+\exp \left(\delta_{c n}\left(\bar{p}_{c n}, \bar{q}_{c n}, \bar{Y}_{i n}, \xi_{c n} ; \omega_{i}\right)\right)+\exp \left(\delta_{s n}\left(\bar{p}_{s n}, \bar{q}_{s n}, \bar{Y}_{i n}, \xi_{s n} ; \omega_{i}\right)\right)} d F\left(\omega_{i}\right)
$$

From the definition of $\delta_{g n}(\cdot)$ and equation (8) it follows that

$$
s_{g n}=s_{g n}\left(\bar{p}_{c n}, \bar{q}_{c n}, \bar{p}_{s n}, \bar{q}_{s n}, \bar{Y}_{n}, \xi_{c n}, \xi_{s n} ; \theta_{d}\right) \text {, }
$$

where $\xi_{c n}$ and $\xi_{s n}$ are the only two unobservable to the econometrician provider characteristics and $\theta_{d}$ is a vector of demand parameters that includes parameters governing the distribution of $\omega_{i}$ and measuring the influence of demographic variables, $\bar{Y}_{n}$.

\footnotetext{
${ }^{23}$ In the empirical model below, they will include random coefficients on price and quality.
} 
Under standard assumptions, we can use the Berry (1994) and Berry, Levinsohn, and Pakes (1995) inversion to solve the system of equations

$$
\left\{\begin{array}{l}
s_{c n}=s_{c n}\left(\bar{p}_{c n}, \bar{q}_{c n}, \bar{p}_{s n}, \bar{q}_{s n}, \bar{Y}_{n}, \xi_{c n}, \xi_{s n} ; \theta_{d}\right) \\
s_{s n}=s_{s n}\left(\bar{p}_{c n}, \bar{q}_{c n}, \bar{p}_{s n}, \bar{q}_{s n}, \bar{Y}_{n}, \xi_{c n}, \xi_{s n} ; \theta_{d}\right)
\end{array}\right.
$$

for a pair $\left(\xi_{c n}, \xi_{s n}\right)$ that makes observed cable and satellite market shares (left-hand-side variables) equal to the ones predicted by our model.

Conditional Product-Specific Shares.-For most markets in our data, we do not observe product-specific shares. However, for the markets for which product-specific shares are available, we do not discard them as they are informative about consumer price and quality preference parameters. Hence, to incorporate these data, let $P_{j g n}\left(\omega_{i}\right)$ denote the probability that consumer type $i$ chooses product $j$ of provider $g$ in market $n$. Let $s_{j \mid g, n}$ denote the market share of tier $j$ given the choice of provider $g$ with $\sum_{j \in \mathcal{J}_{g n}} s_{j \mid g, n}=1$ by construction. Then the model's prediction for this share is described by the following equation:

$$
s_{j \mid g, n}=\frac{\int \mathbf{1}\left(j=\arg \max _{j^{\prime} \in \mathcal{J}_{g}}\left\{\delta_{g j^{\prime}}\left(p_{g j^{\prime}}, q_{g j^{\prime}}, \bar{Y}_{i n}, \xi_{g} ; \omega_{i}\right)\right\} P_{g n}\left(\omega_{i}\right) d F\left(\omega_{i}\right)\right.}{\int P_{g n}\left(\omega_{i}\right) d F\left(\omega_{i}\right)} .
$$

Since there are no structural errors here, we introduce measurement error $u$ to explain differences between predicted and observed values of product-specific shares,

$$
\begin{gathered}
s_{j \mid g, n}=s_{j \mid g, n}\left(\bar{p}_{c n}, \bar{q}_{c n}, \bar{p}_{s n}, \bar{q}_{s n}, \bar{Y}_{n}, \xi_{c n}, \xi_{s n} ; \theta_{d}\right)+u_{g j n} . \\
\text { B. Supply }
\end{gathered}
$$

We model optimal price and quality decisions by the local cable system in each market, $n$. As alluded to earlier, we treat satellite providers' prices and products as set exogenously.

ASSUMPTION 1: The satellite competitor is a nonstrategic player in the sense that it does not react to policies (prices, qualities) chosen by local cable systems.

The per-subscriber marginal cost of providing product $j$ in market $n$ is

$$
m c_{c j n}=m c\left(q_{c j n}, Z_{c n} ; \theta_{s}\right)
$$

where $Z_{c n}$ denotes a vector of observable cost shifters, and $\theta_{s}$ is a vector of supply-side cost parameters. Together with the assumption that market size does not change over time, this allows us to write the maximization problem for a cable system as follows:

$$
\max _{\left\{p_{c j n}, q_{c j n}\right\}_{j \in \mathcal{J}_{c n}}}\left\{\sum_{j \in \mathcal{J}_{c n}} s_{c j n}\left(\bar{p}_{c n}, \bar{q}_{c n}, \bar{p}_{s n}, \bar{q}_{s n}, \xi_{c n}, \xi_{s n} ; \theta_{d}\right)\left(p_{c j n}-m c\left(q_{c j n}, Z_{c n} ; \theta_{s}\right)\right)\right\}
$$


This specification assumes that the marginal quantity cost of providing cable service is constant across subscribers (i.e., no economies or diseconomies of scale), but that this (constant) marginal cost increases with the quality of the offered service. This specification fits well the cable industry where the most important marginal costs facing systems are the input costs (affiliate fees) paid to television networks, which are constant per-subscriber fees. ${ }^{24}$

The first-order conditions for cable operators' price and quality are

$$
\begin{aligned}
& \text { F.O.C. }\left[p_{c j n}\right]: \quad s_{c j n}+\sum_{r \in \mathcal{J}_{c n}}\left(p_{c r n}-m c_{c r n}\right) \frac{\partial s_{c r n}}{\partial p_{c j n}}=0 \text {, } \\
& \text { F.O.C. }\left[q_{c j n}\right]: \quad-\frac{\partial m c_{c j n}}{\partial q_{c j n}} s_{c j n}+\sum_{r \in \mathcal{J}_{c n}}\left(p_{c r n}-m c_{c r n}\right) \frac{\partial s_{c r n}}{\partial q_{c j n}}=0 .
\end{aligned}
$$

Equations (14) and (15) can be solved for the marginal cost levels, $m c_{c j n}$, and the derivatives of the marginal cost function, $\partial m c_{c j n} / \partial q_{c j n}$, that rationalize observed price and quality choices given the parameters of the model (more on this in Section IVB).

We take the number of products offered by each cable system as given and exogenous to systems' price and quality decisions. This is reasonable in cable markets because the number of products offered by cable systems often depends on the technology the system has in place and therefore plausibly exogenous to annual price and quality decisions. 25

\section{Specification and Estimation}

Here we fill in specification details for consumers' utility and cable systems' cost functions.

\section{A. Demand}

On the demand side, we assume that consumer utility net of additive i.i.d. shocks $\epsilon_{i g n}$ is a linear function of price, quality, and demographic characteristics, $\bar{Y}_{i n}$ :

$$
\delta_{g j n}\left(p_{g j n}, q_{g j n}, \bar{Y}_{i n}, \xi_{g} ; \omega_{i}\right)=\alpha_{i p}\left(\bar{Y}_{i n}\right) p_{g j n}+\alpha_{i q}\left(\bar{Y}_{i n}\right) q_{g j n}+\xi_{g n},
$$

where

$$
\begin{aligned}
& \alpha_{i p}=a_{i 0}+a_{y} I_{n}+a_{h} H_{n}+a_{u} U_{n}, \\
& \alpha_{i q}=b_{i 0}+b_{y} I_{n}+b_{h} H_{n}+b_{u} U_{n},
\end{aligned}
$$

\footnotetext{
${ }^{24}$ See Crawford and Yurukoglu (2012) for more details about these contracts.

${ }^{25}$ Similar timing assumptions are invoked in the empirical measurement of productivity (e.g., Olley and Pakes 1996, Ackerberg, Caves, and Frazer 2015). More generally, the model in the paper can be thought of as the second stage of a larger model in which firms choose first the number of products before choosing the quality levels of each product. As such, we should interpret our findings of quality overprovision below as a short-run effect when adjusting the number of products is not possible; in the long run, such distortions may change as firms change the number of products they offer.
} 
and $I_{n}$ stands for income, $H_{n}$ for household size, and $U_{n}$ for the level of urbanization in market $n$. These market-level variables are assumed to have the same effect on the price and quality sensitivity parameters for all consumer types. Two additional parameters $a_{i 0}$ and $b_{i 0}$ are $i$-specific and have a flexible variance-covariance matrix, i.e.,

$$
\left(\begin{array}{l}
a_{i 0} \\
b_{i 0}
\end{array}\right) \sim N\left(\begin{array}{l}
\bar{a}_{0} \\
\bar{b}_{0}, \Sigma
\end{array}\right), \quad \Sigma=\left(\begin{array}{ll}
\sigma_{a}^{2} & \rho_{a b} \\
\rho_{a b} & \sigma_{b}^{2}
\end{array}\right)
$$

On the demand side we estimate the parameters

$$
\theta_{d}=\left(\alpha_{c}, \alpha_{s},\left[\bar{a}_{0}, a_{y}, a_{h}, a_{u}\right],\left[\bar{b}_{0}, b_{y}, b_{h}, b_{u}\right], \sigma_{a}, \sigma_{b}, \rho_{a b}\right)
$$

\section{B. Supply}

In order to evaluate the counterfactuals for the social planner's quality choices, we need to know the entire marginal cost function for each cable operator, not just the costs at the observed quality levels. ${ }^{26}$ Hence, we specify a flexible yet parsimonious specification for the marginal cost function:

$$
m c\left(q_{c j n}, Z_{c n} ; \theta_{s}\right)=\exp \left(c_{0 j n}+c_{1 j n} q_{j c n}\right)
$$

The exponential functional form is consistent with the cable systems' facing technological capacity constraints when adding high-quality networks into their channel lineup. 27

We follow the existing literature (e.g., Berry, Levinsohn, and Pakes 1995) to generate moment restrictions for the supply-side. For a given vector of parameter values, we can solve the supply-side first-order conditions to obtain estimates of the marginal costs $\widehat{m c}_{c j n}$ and $\partial \widehat{m c}_{c j n} / \partial q_{c j n}$, which in turn are used to compute $\hat{c}_{0 j n}$ and $\hat{c}_{1 j n}$ as follows:

$$
\begin{aligned}
\hat{c}_{0 j n} & =\ln \left(\widehat{m c}_{c j n}\right)-\frac{\partial \widehat{m c}_{c j n} / \partial q_{c j n}}{\widehat{m c}_{c j n}} q_{c j n}, \\
\hat{c}_{1 j n} & =\frac{\partial \widehat{m c}_{c j n} / \partial q_{c j n}}{\widehat{m c}_{c j n}} .
\end{aligned}
$$

\footnotetext{
${ }^{26}$ As usual in these models, since we base estimation on suppliers' first-order conditions, we cannot model their fixed costs. However, the data show that quality levels are not systematically higher in larger markets (the graphs are available upon request), implying that the scale of the firm is not playing a big role in its quality choices.

${ }^{27}$ The particular functional form chosen for the marginal cost function is not critical for the identification of model parameters. In principle, with more products for each producer, we could add additional parameters into the marginal cost function for a less parsimonious specification.
} 
In turn, we assume that these coefficients can be specified as linear functions of observable cost shifters and a pair of structural error terms, $\left(\nu_{0 c j n}, \nu_{1 c j n}\right) \cdot{ }^{28}$ That is, we project $\hat{c}_{0 j n}$ and $\hat{c}_{1 j n}$ on $Z_{c n}$, i.e.,

$$
\begin{aligned}
& \hat{c}_{0 j n}=Z_{c j n} \theta_{s 0}+\nu_{0 c j n}, \\
& \hat{c}_{1 j n}=Z_{c j n} \theta_{s 1}+\nu_{1 c j n},
\end{aligned}
$$

to recover $\nu_{1 c j n}$ and $\nu_{2 c j n}$ satisfying

$$
\begin{aligned}
& E\left[\nu_{0 c j n} \mid Z_{c j n}\right]=E\left[\nu_{1 c j n} \mid Z_{c j n}\right]=0 . \\
& \text { C. Instruments and Identification }
\end{aligned}
$$

As we discussed in Section IIIA, for each value of the parameter vector $\theta_{d}$, we solve for a pair of provider-specific structural errors, $\left(\xi_{c n}, \xi_{s n}\right)$, and a set of non-structural measurement errors, $u_{c j n}$, for cable providers using aggregate cable and satellite market shares, prices and observed quality levels for each tier offered, and tier-specific cable market shares. On the supply side, we described in the previous section how we obtain, for each parameter vector, the pair of structural errors $\left(\nu_{1 c j n}, \nu_{2 c j n}\right)$ per product. Identification of the structural parameters relies on a set of conditional independence assumptions summarized by Assumption 2.29

ASSUMPTION 2: Unobservables and identifying assumptions:

(i) For each service provider $g$ in market $n$, the unobserved service characteristics can be written as

$$
\xi_{g n}=\bar{\alpha}_{g}+\alpha_{g t}+\tilde{\xi}_{g n}
$$

where $\bar{\alpha}_{g}$ is provider-specific intercept, $\alpha_{g t}$ is provider-specific time effect, and $\left(\tilde{\xi}_{c n}, \tilde{\xi}_{s n}\right)$ satisfy the following mean independence assumptions,

$$
E\left[\tilde{\xi}_{c n} \mid \bar{Z}_{c n}\right]=E\left[\tilde{\xi}_{s n} \mid \bar{Z}_{s n}\right]=0
$$

(ii) Measurement errors for markets with 2 and 3 cable products satisfy

$$
E\left[u_{c j n} \mid \bar{Z}_{c n}\right]=0, \quad j=1,2 .
$$

\footnotetext{
${ }^{28}$ We refer to the errors as "structural" because they are observed by cable system before price and quality decisions are made.

${ }^{29}$ While the assumption suggests that the instrumental variables for cable and satellite innovations, $\bar{Z}_{c n}$ and $\bar{Z}_{s n}$, can be different (e.g., we can use own satellite price and quality as instruments for satellite own innovations) we use more conservative assumption that $\bar{Z}_{s n}=\bar{Z}_{c n}$.
} 
(iii) Supply-side cost shocks for each product offered are linear functions of cost shifters,

$$
\begin{aligned}
& c_{0 j n}=\bar{Z}_{c n} \theta_{s 0}+\nu_{0 c j n}, \\
& c_{1 j n}=\bar{Z}_{c n} \theta_{s 1}+\nu_{1 c j n},
\end{aligned}
$$

where

$$
E\left[\nu_{0 c j n} \mid \bar{Y}_{n}, \bar{Z}_{c n}\right]=E\left[\nu_{1 c j n} \mid \bar{Y}_{n}, \bar{Z}_{c n}\right]=0
$$

It is worth noting that in estimation we control for carrier-time demand side fixed effects, $\alpha_{g t}$, i.e., we control for time effects, which vary by service provider (cable or satellite). Similarly, we use carrier-time dummies on the supply side as well, i.e., $\bar{Z}_{c n}$ contains these variables.

There is an obvious endogeneity problem because cable companies observe realizations of $\left(\xi_{c n}, \xi_{s n}\right)$ prior to making their price and quality choices. Therefore, prices and qualities are likely to be correlated with the unobserved service characteristics, $\xi_{c n}$ and $\xi_{s n}$. For finding instruments, we use the following arguments, adapted from Shcherbakov (2016).

First, we assume that the average prices and quality levels of other cable systems that belong to the same multiple system operator (MSO) are valid instrumental variables for prices and quality levels of the local provider. We assume that these variables are uncorrelated with the unobserved local market service characteristics, $\xi_{\cdot n}$, but are reasonable proxies for the price and quality levels offered by the local cable system. Correlation in prices and quality levels across systems exists because the owner of several cable systems typically negotiates programming fees and other contract arrangements with programming networks on behalf of all of its members simultaneously. In turn, correlation in the marginal costs of systems within the same MSO justifies correlation in their price and quality levels. At the same time, for the instruments to be valid, one must ensure that the unobserved demand shocks, $\xi_{. n}$ are not correlated across markets. For example, this would be a concern if there were national advertising of cable products across the markets owned by a single MSO; fortunately for this specification, this is not the case in cable markets during our sample period. 30

Second, different MSOs have different bargaining power in negotiations with programming networks. It may be that larger MSOs (i.e., those with more total subscribers) have stronger bargaining positions. Hence, we use the number of MSO subscribers as a cost shifter. ${ }^{31}$ Third, programming networks often sell bundles consisting of several channels. The ability to purchase such bundles depends on the

\footnotetext{
${ }^{30}$ Crawford (2008) discusses this class of instruments in detail and why they work well in cable markets.

${ }^{31}$ Crawford and Yurukoglu (2012) found that large MSOs were estimated to have more bargaining power than small MSOs and satellite providers. Indeed, the logic that larger systems are able to obtain better wholesale prices for channels underlies the choice of some of our demand-side instrumental variables. Such an effect could provide an alternative "cost-side" explanation for quality overprovision. However, one way to disentangle this from the "demand-side" quality overprovision of the Champsaur and Rochet (1989) theory is to note that the bargaining power story does not depend on DBS presence whereas, as we will demonstrate below, the quality overprovision we document obtains only when a DBS competitor is present.
} 
system's channel capacity. Thus, average channel capacity within an MSO should be correlated with the ability of their member-systems to get lower rates. By the same logic, we used own capacity level as another instrumental variable. Fourth, total length of own coaxial lines of the local cable systems is a proxy for the differences in maintenance costs incurred by the systems in areas with different densities of houses.

Our baseline set of instruments includes all of these variables. To demonstrate the effects of the instruments and for robustness, however, we also consider specifications in which all variables instrument for themselves (hereafter OLS-type instruments) and using a minimal set of instruments consisting only of the ownership-based (MSO) instruments (hereafter min-IV). These results are reported in Table 12 together with additional robustness checks for alternative measures of quality in Table 13.

There are three sets of moment conditions as described by Assumption (2): (i) moments associated with the unobserved product characteristics (i.e., demand-side shocks), (ii) moments associated with the supply-side shocks, and (iii) measurement errors in conditional cable shares. Measurement errors in conditional cable product shares are uncorrelated with other variables by definition. We also assume no correlation between demand- and supply-side innovations. However, demand side unobservables for cable and satellite can be correlated with each other, i.e., $\operatorname{cov}\left(\xi_{c n}, \xi_{s n}\right) \neq 0$. We exploit this information when constructing the weighting matrix and criterion function for the estimation. ${ }^{32}$ The structural parameters are estimated by GMM with an optimal weighting matrix.

\section{Estimation Results}

\section{A. Parameter Estimates}

Demand.-Table 5 summarizes our estimation results for two specifications. Specification (2) includes demographics at the market level, while specification (1) omits them. While demographic variables appear to be quite important determinants of the price sensitivity, they are not statistically significant determinants of preferences for quality. Parameters of the distribution of unobserved consumer heterogeneity are statistically significant with tastes for quality having much wider dispersion than price sensitivity. Figure 2 describes the estimated distributions of price and quality parameters across markets.

Turning to the estimates for $\rho_{a b}$, the correlation between the random coefficients on price and quality, we see that without demographic controls, this correlation is an estimated -0.545 , indicating that the most price sensitive consumers also have the greatest quality sensitivity. ${ }^{33}$ Once market-level demographics are included, the

\footnotetext{
${ }^{32}$ In particular, individual moments based on $\tilde{\xi}_{c n}$ and $\tilde{\xi}_{s n}$ are "stacked" horizontally and are treated as distinct moment conditions, i.e., averaging is done separately for cable and satellite moments. In contrast, in Berry, Levinsohn, and Pakes (1995) and the following literature, the averaging for the moment conditions is across the available products, which in our case would be the cable and satellite products.

${ }^{33}$ Trends in the home television market after the sample period offer evidence in line with this finding of negative correlation. In particular, in recent years the phenomenon of "cord cutting" has been documented, in which cable (and satellite, to a lesser extent) consumers have terminated their service in favor of outside options such as streaming services (eg. Netflix, Apple TV, etc.). This practice is particularly pronounced among higher income, young professionals
} 
Table 5-Estimation Results

\begin{tabular}{|c|c|c|c|c|}
\hline & Coefficient & SE & Coefficient & SE \\
\hline & \multicolumn{2}{|c|}{ (1) } & \multicolumn{2}{|c|}{ (2) } \\
\hline \multicolumn{5}{|l|}{ Price coefficient, $\alpha_{i p}$} \\
\hline Mean & -0.673 & $(0.008)$ & -0.682 & $(0.035)$ \\
\hline Income & & & -0.418 & $(0.147)$ \\
\hline Household size & & & 0.396 & $(0.271)$ \\
\hline Urban & & & -0.173 & $(0.177)$ \\
\hline Sigma & 0.102 & $(0.018)$ & 0.122 & $(0.018)$ \\
\hline \multicolumn{5}{|l|}{ Price coefficient, $\alpha_{i q}$} \\
\hline Mean & 1.108 & $(0.121)$ & 1.225 & $(0.241)$ \\
\hline Income & & & -0.337 & $(0.777)$ \\
\hline Household size & & & 0.221 & $(1.395)$ \\
\hline Urban & & & 0.331 & $(0.917)$ \\
\hline Sigma & 0.310 & $(0.020)$ & 0.266 & $(0.048)$ \\
\hline$\rho_{a b}$ & -0.545 & $(0.128)$ & -0.481 & $(0.049)$ \\
\hline Demand $t$-dummies & Yes & & Yes & \\
\hline Supply $t$-dummies & Yes & & Yes & \\
\hline
\end{tabular}

Notes: Reported are estimation results for key parameters from our structural model of demand, price, and quality choice. There are 12,214 observations, where an observation is a cable system-product-year. Full estimation results can be found in Appendix C. Specification (1) does not include market demographics in preferences, while specification (2) does. Standard errors are clustered by market and listed in parentheses. Instruments include all those described in Section IVC; results using each variable as its own instrument (OLS-type) and a minimal set of instruments based on ownership (MSO) measures (min-IV) are presented in Appendix B. First-stage regressions are reported in Appendix D.
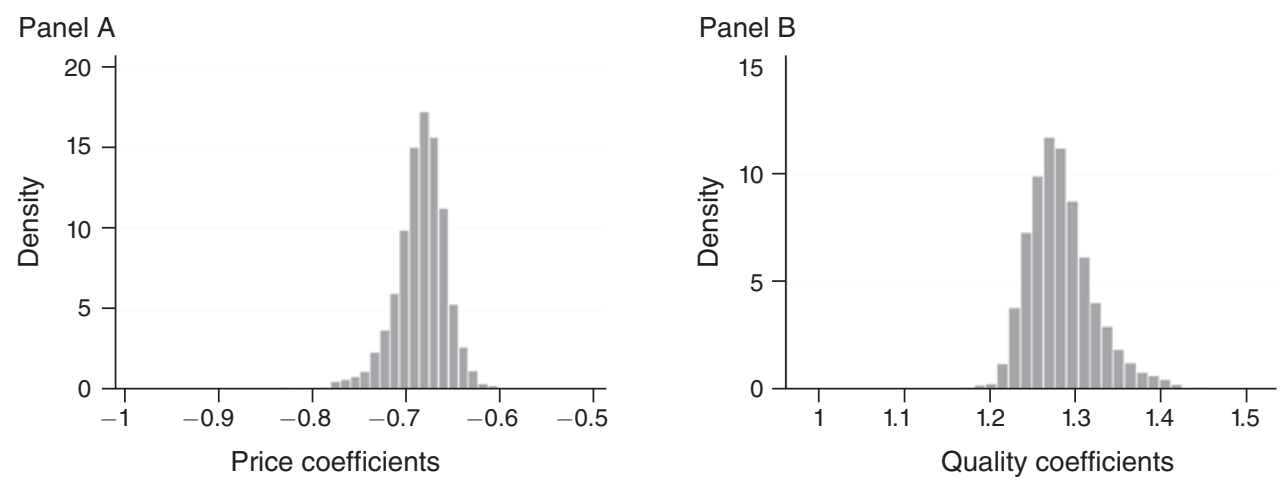

Figure 2. Distributions of Mean Price and Quality Parameters across Markets

Note: Reported are the estimated distributions of mean price and quality parameters across markets implied by the parameter estimates reported in Table 5.

correlation in unobserved tastes for price and quality falls (in magnitude) to an estimated -0.481 . Additionally, to illustrate the implications of these estimates of the consumer heterogeneity parameters on demand, Figures 8 and 9 display the

and demonstrates that these individuals, who plausibly have higher tastes for quality, may be those who are most sensitive to cable prices. 
consumer purchase probabilities for cable and satellite products for different consumer types (as given by their random coefficient parameters).

Estimated own-price elasticities across markets average -52 for one-good markets, and -5.3 in multi-good (both 2 and 3 products) markets. ${ }^{34}$ The magnitude of these elasticities are similar to those found in the literature. ${ }^{35}$

Results for two alternative specifications are reported in Appendix B. In an OLSlike specification, in which price and quality are treated as exogenous, yields a mean price coefficient of -0.553 , showing that instrumenting has the expected effect of making estimated demand more elastic. A second alternative specification using a minimal set of instruments yields qualitatively similar results, but with larger standard errors. The estimated negative correlation $\rho_{a b}$ is robust in these specifications. For this reason, we rely on our baseline specification presented in column 2 for our counterfactual simulations.

Supply.-The estimated distributions of marginal costs and their derivatives at observed quality levels are reported in Table 6. These suggest substantial variability in terms of technology levels (as implied by the cost function estimates) used by cable systems. Using these estimates, we construct a flexible estimate of a firm's marginal cost function by using a flexible spline (Hermite) interpolation between the marginal cost levels and derivatives estimated at the observed quality levels, as reported in Table 6, and using the exponential specification (equation (20)) for extrapolation outside this range. Accordingly, for 1-product markets the marginal cost function is completely exponential. For 2- and 3-product markets it is exponential outside the range of the observed quality levels, and a monotone Hermite spline in-between. By doing this we are able to obtain a marginal cost function which utilizes all the information from the estimates in Table 6 , and yet is monotone, continuous, and continuously differentiable, which are convenient features for computing counterfactuals.

Figure 3 shows estimated marginal cost functions for 1-, 2-, and 3-product firms implied by our estimates. As is apparent, high-quality systems on average have lower and flatter (less steeply increasing) marginal costs, perhaps as a result of using more advanced technology. Single-product firms have the highest and steepest marginal cost curves.

\section{B. Welfare Effects from Endogenous Quality}

To quantify firms' quality distortions in this market, we need to compare observed outcomes with counterfactual ones given by a social planner. The social planner problem is to maximize total surplus, defined as the sum of consumer surplus and producer profit.

\footnotetext{
${ }^{34}$ Histograms and further summary statistics for own price elasticities across markets are reported in Appendix A. Average estimated price-cost markups implied by these elasticity estimates are reported in Table 10.

${ }^{35}$ For example, Crawford et al. (2018) find elasticities ranging from -1.7 to -4.2 and Crawford and Yurukoglu (2012) find elasticities ranging from -4.1 to -6.3 . The latter also cites additional papers that find elasticities ranging from a low of -1.5 to -5.9 , depending on the product and platform considered.
} 
Table 6-Summary Statistics for the Supply-Side Estimates

\begin{tabular}{|c|c|c|c|c|c|}
\hline & Mean & Median & Min & Max & SD \\
\hline \multicolumn{6}{|c|}{ System type: 1-product } \\
\hline$m c_{c 0}$ & 16.81 & 17.15 & 0.03 & 46.79 & 5.79 \\
\hline$\partial m c_{c 0} / \partial q_{c 0}$ & 1.90 & 1.90 & 1.03 & 2.96 & 0.13 \\
\hline \multicolumn{6}{|c|}{ System type: 2-product } \\
\hline$m c_{c 0}$ & 13.36 & 11.44 & 0.00 & 70.42 & 9.42 \\
\hline$m c_{c 1}$ & 25.47 & 22.53 & 1.50 & 96.06 & 11.93 \\
\hline$\partial m c_{c 0} / \partial q_{c 0}$ & 1.79 & 1.84 & 0.07 & 2.41 & 0.25 \\
\hline$\partial m c_{c 1} / \partial q_{c 1}$ & 13.49 & 7.41 & 0.66 & 114.75 & 13.71 \\
\hline \multicolumn{6}{|c|}{ System type: 3-product } \\
\hline$m c_{c 0}$ & 12.88 & 12.16 & 0.06 & 60.46 & 8.58 \\
\hline$m c_{c 1}$ & 28.61 & 26.31 & 2.20 & 99.36 & 12.97 \\
\hline$m c_{c 2}$ & 47.80 & 45.12 & 11.46 & 119.67 & 17.43 \\
\hline$\partial m c_{c 0} / \partial q_{c 0}$ & 1.77 & 1.83 & 0.12 & 2.40 & 0.26 \\
\hline$\partial m c_{1} / \partial q_{c 1}$ & 4.03 & 3.64 & 0.27 & 14.31 & 1.89 \\
\hline$\partial m c_{c 2} / \partial q_{c 2}$ & 20.79 & 16.73 & 2.04 & 129.47 & 14.74 \\
\hline
\end{tabular}

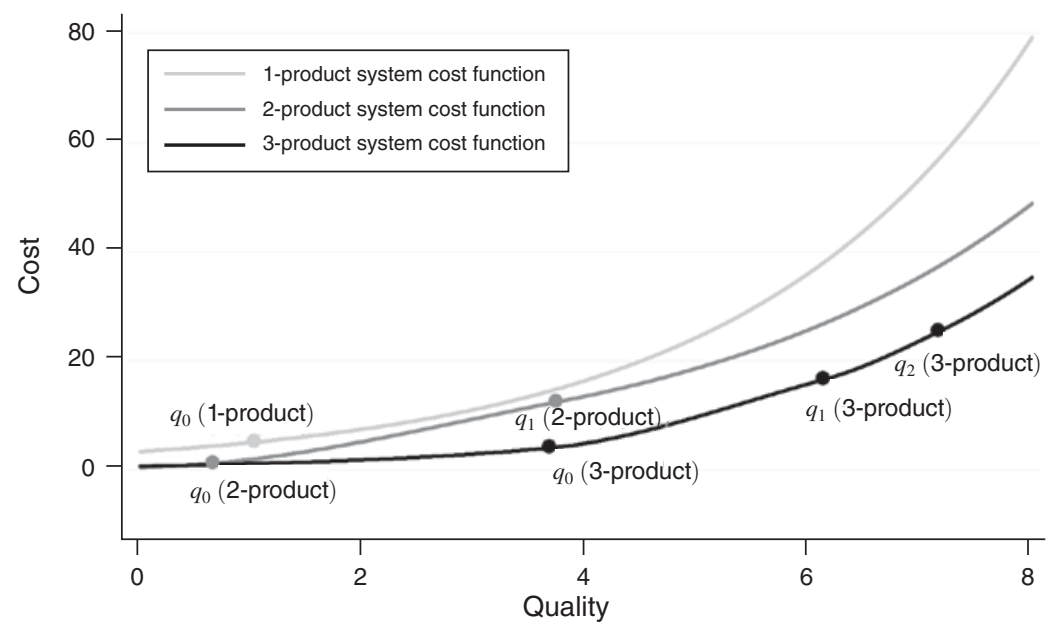

Figure 3. Estimated Marginal Cost Functions by System Type

Note: Reported are the estimated marginal cost functions by system type (1-, 2-, or 3-product) and by product within each system type implied by the parameter estimates reported in Table 6.

Let $\alpha_{i p}$ denote the price sensitivity of consumer type $i$. The expected consumer surplus $\left(C S_{i n}\right)$ for type $i$ in market $n$ is then defined as

$$
\begin{aligned}
E\left(C S_{i n}\right) & =-\frac{1}{\alpha_{i p}} E_{\epsilon}\left[\max _{g j n}\left\{u_{i g i n}\right\}\right] \\
& \left.=-\frac{1}{\alpha_{i p}} \ln \left(1+\sum_{g=c, s} \exp \left(\delta_{g j n}\left(p_{g j n}, q_{g j n}, \bar{Y}_{i n}, \xi_{g} ; \omega_{i}\right\}\right)\right)\right),
\end{aligned}
$$


where $u_{i g j n}$ is given by equation (5), and the second line follows from the distributional assumption on $\epsilon_{i g n}$. Total consumer surplus in market $n$ is then obtained by integrating over the distribution of consumer heterogeneity, i.e.,

$$
\left.E\left(C S_{n}\right)=-\int \frac{1}{\alpha_{i p}} \ln \left(1+\sum_{g=c, s} \exp \left(\delta_{g j n}\left(p_{g j n}, q_{g j n}, \bar{Y}_{i n}, \xi_{g} ; \omega_{i}\right\}\right)\right)\right) d F\left(\omega_{i}\right)
$$

Accordingly, the first-order conditions for the social planner are

$$
\begin{array}{ll}
\text { F.O.C. }{ }^{S P}\left[p_{c j n}\right]: & \frac{\partial \Pi(\cdot)}{\partial p_{c j n}}+\frac{\partial E\left(C S_{n}\right)}{\partial p_{c j n}}=0, \\
\text { F.O.C. }{ }^{S P}\left[q_{c j n}\right]: & \frac{\partial \Pi(\cdot)}{\partial q_{c j n}}+\frac{\partial E\left(C S_{n}\right)}{\partial q_{c j n}}=0,
\end{array}
$$

where $\partial \Pi(\cdot) / \partial p_{c j n}$ and $\partial \Pi(\cdot) / \partial q_{c j n}$ were given earlier by the left-hand sides of equations (14) and (15) respectively.

We calculate the optimal social planner's quality and price using (24) and (25), given our estimates of consumer preferences and operator cost functions described in the previous section. The results are summarized in Table 7. Table 11 reports detailed factual and counterfactual price and quality levels.

Turning first to column 1, we find, at observed prices, monopoly cable operators underprovide (or degrade) quality: the quality of low-quality products provided by a social planner are predicted to increase by 55 percent, while qualities for mediumand high-quality products by are predicted to increase by 7 percent. Consumers surplus increases by an estimated 43 percent, firm profits fall by an estimated 33 percent, and total surplus increases by an estimated 10 percent. The quality degradation finding here is not surprising as, with prices fixed, the socially optimal quality level is that at which the marginal cost of quality is exactly equal to the price; hence, for the monopolist to overprovide quality at fixed prices is impossible as that would imply setting quality at a level where the marginal cost of quality exceeds the price, which neither the monopolist nor social planner would do.

In column 2, we hold fixed qualities at the social optimum levels, and consider lowering prices from the observed levels to marginal cost (the socially optimal price level). The results indicate that market power over price is also important. Prices fall between an estimated 33 percent and 74 percent, consumer surplus rises by an estimated 54 percent, profits are eliminated by marginal cost pricing, and total surplus increases by 7 percent.

Column 3 contains the most interesting patterns. The results from the third counterfactual show that, when the social planner jointly sets prices and qualities, he would set quality levels to be lower than the monopolists' choices, i.e., the opposite of the quality degradation shown in column A. On average, socially optimal qualities would be lower by between 23 percent and 55 percent compared to observed values (and by between 45 percent and 58 percent compared to the social planner's qualities at observed prices in column 1). This suggests that cable companies are offering consumers overly large bundles of channels at correspondingly inflated prices; instead consumers would prefer smaller (lower-quality) bundles at lower prices. At the social optimum, consumer surplus more than doubles (+116 percent): an effect far greater 
Table 7-Welfare Effects of Market Power over Quality (and Price)

\begin{tabular}{|c|c|c|c|c|c|c|}
\hline & \multicolumn{2}{|c|}{$\begin{array}{c}\text { Market power } \\
\text { over quality } \\
\left(p^{O b s}, q^{O b s}\right) \text { vs. }\left(p^{O b s}, q^{S P}\right)\end{array}$} & \multicolumn{2}{|c|}{$\begin{array}{c}\text { Market power } \\
\text { over price } \\
\left(p^{O b s}, q^{S P}\right) \text { vs. }\left(p^{S P}, q^{S P}\right)\end{array}$} & \multicolumn{2}{|c|}{$\begin{array}{c}\text { Total welfare effect } \\
\left(p^{O b s}, q^{O b s}\right) \text { vs. }\left(p^{S P}, q^{S P}\right)\end{array}$} \\
\hline & Mean & SD & Mean & SD & Mean & SD \\
\hline & \multicolumn{2}{|c|}{ (1) } & \multicolumn{2}{|c|}{ (2) } & \multicolumn{2}{|c|}{ (3) } \\
\hline \multicolumn{7}{|l|}{ Prices } \\
\hline Low-quality products & - & - & -0.330 & 0.180 & -0.330 & 0.180 \\
\hline Medium-quality products & - & - & -0.590 & 0.220 & -0.590 & 0.220 \\
\hline High-quality products & - & - & -0.740 & 0.130 & -0.740 & 0.130 \\
\hline \multicolumn{7}{|l|}{ Qualities } \\
\hline Low-quality products & 0.550 & 0.720 & - & - & -0.230 & 0.910 \\
\hline Medium-quality products & 0.070 & 0.110 & - & - & -0.370 & 0.410 \\
\hline High-quality products & 0.070 & 0.040 & - & - & -0.550 & 0.260 \\
\hline \multicolumn{7}{|l|}{ Welfare } \\
\hline Consumer surplus & 0.430 & 0.290 & 0.540 & 0.420 & 1.160 & 0.520 \\
\hline Profit & -0.330 & 0.240 & -1.000 & - & -1.000 & - \\
\hline Total surplus & 0.100 & 0.060 & 0.070 & 0.050 & 0.170 & 0.070 \\
\hline
\end{tabular}

Note: Numbers in this table are proportional changes, relative to the baseline scenarios (at observed prices and qualities).

than the effect of efficient qualities or prices on their own, and total surplus increases by an estimated 17 percent.

Furthermore, when we examine the overprovision result market-by-market, we find that multi-product cable firms tend to overprovide quality more often than single-product systems. This is illustrated in Figure 4, which describes the frequency of under- and overprovision in 1-, 2-, and 3-product markets. It is evident from these graphs that there is a much higher preponderance of quality overprovision in multi-good markets, compared to single-good markets. Panel A of Figure 4, corresponding to single-product markets, has most of its mass at positive values of the normalized quality difference $\frac{q^{T S-\max }-q^{\pi-\max }}{q^{\pi-\max }}$, implying quality degradation; in contrast, the remaining histograms, corresponding to two- and three-good markets, have most of the mass at negative values, implying quality overprovision.

Such results are new and surprising relative to the literature. The classic results from Mussa and Rosen (1978) predict only quality degradation. However, Spence (1975) shows that a monopolist can choose to overprovide quality (relative to the social planner) depending on the curvature of the demand curve Moreover, in a modified Mussa-Rosen model in which consumers have a high-end outside option, Champsaur and Rochet (1989, Section 3) show that the monopolist can optimally overprovide quality. In the next section we explore these potential explanations for our quality overprovision result.

\section{Inside the Black Box: Explaining Quality Overprovision}

The quality overprovision from the previous section is at odds with the results from the screening literature described in Section I, which typically predicts quality degradation for low consumer types and no distortions at the top. In this section 

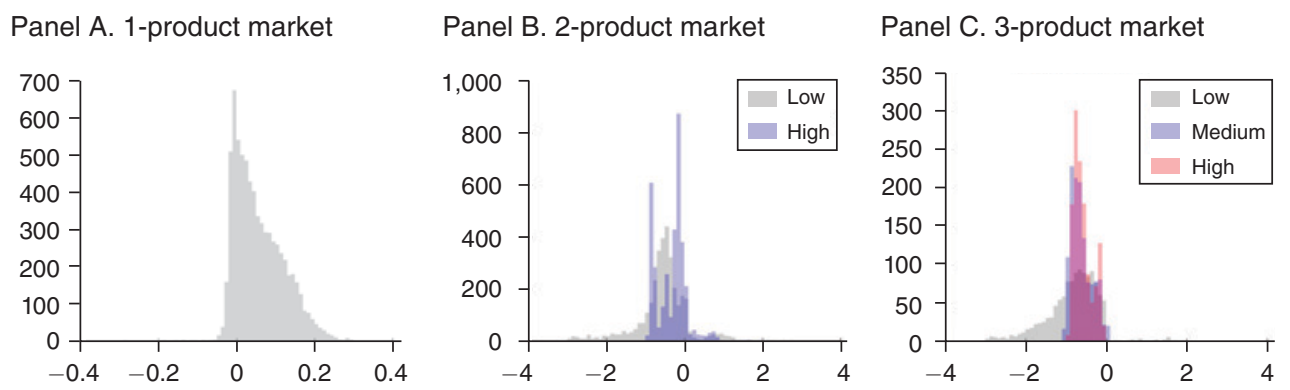

Figure 4. Quality Inflation for Each Product by Type of Cable System

we assess possible explanations for the quality overprovision that we find. One is provided by Spence (1975) where the marginal valuation of quality increases more for high-willingness-to-pay consumers. An alternative to this preference-based explanation is one provided by Champsaur and Rochet (1989), who show that when the monopolist faces competition from a high-end competitor offering consumers a high-quality outside option (in contrast to the low-quality outside option assumed in most nonlinear pricing models), then it may optimally choose to distort qualities upward relative to the first-best. Indeed, in the cable setting, the relevant outside option is satellite TV, which is reasonable to characterize as a high-end product (as satellite TV bundles typically offer more channels).

Given that our quality overprovision result goes against conventional wisdom in much of the nonlinear pricing literature, we also examine its robustness. In this section we report results from a wide range of simulations to examine the robustness of the quality overprovision result to changes in key demand model parameters. Specifically, we estimated a negative correlation (i.e., $\rho<0$ ) between the random coefficients on prices and quality in the demand model. Since it is well recognized in the demand estimation literature that the parameters in the covariance matrix of random coefficients may be delicately identified, ${ }^{36}$ we perform these robustness checks to ensure that our quality overprovision result is not just a spurious artifact arising from the potentially poor identification of these preference parameters.

Since quality overprovision arises primarily in multi-good markets (as shown in Figure 4), we investigate these concerns in a 2-product system. For our benchmark 2-product system, we use Evansville, IL in 1997, in which the cable monopolist was Falcon Cable TV. ${ }^{37}$

Figure 5 presents the results of our simulations for this market. For a wide range of possible values of the correlation parameter $\rho \in[-0.9,0.9]$ we compute profit-maximizing price and quality levels $p_{c j}^{\pi-\max }$ and $q_{c j}^{\pi-\max }$, respectively. We do this under the situation when the DBS competitor is present in the market and under the alternative market structure, where there is no DBS competitor. Then, we calculate socially optimal price and quality levels $p_{c j}^{S P-\max }$ and $q_{c j}^{S P-\max }$, for situations with

\footnotetext{
${ }^{36}$ For that reason, many applications of random coefficient demand models assume that the random coefficients are independent, i.e., have a diagonal covariance matrix.

${ }^{37}$ This market is representative of all 2-product markets in the sense of having smallest Euclidean distance from simple average of each characteristics across systems with the same number of products.
} 
Panel A. With DBS competitor

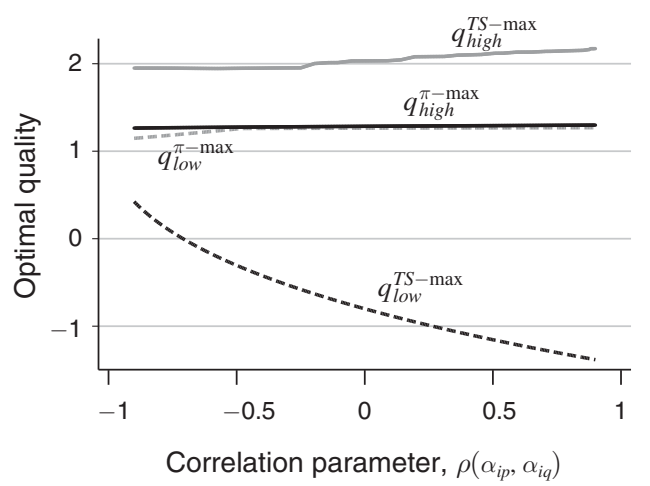

Panel B. Without DBS competitor

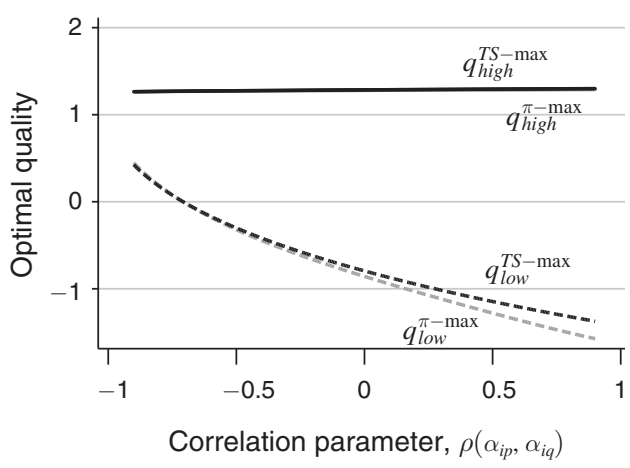

FIGURE 5

Note: Benchmark two-product market (Evansville, IL; 1997): profit and TS maximizing cable quality for monopolist with (panel A) and without (panel B) the presence of DBS competitor.

and without competition from satellite providers. With these quantities we can now illustrate how the degree of under-/overprovision changes for different values of the correlation parameter and how this relationship is affected by competition.

It is apparent that the overprovision result is present for any value of the correlation parameter. Interestingly, comparing the two graphs in Figure 5, the presence of a DBS competitor leads the multi-product cable firm to overprovide quality of both products not only relative to the social planner, but also relative to the quality levels it would choose if the DBS competitor were removed. For example, for the high-quality product $\left(q_{\text {high }}\right)$ we see that, across all values of $\rho$, the monopolist chooses a quality level roughly 80 percent higher than what the social planner chooses when the DBS competitor is present, whereas removing the DBS competition causes the monopolist to choose lower-quality levels identical to that of the social planner. The key takeaway here is that the presence of satellite competition leads cable firms to offer significantly higher-quality levels, thus confirming Champsaur and Rochet's model.

In essence, quality overprovision can be interpreted as a business stealing strategy on the part of cable companies vis-á-vis their satellite competitors. An important feature of satellite competition is that satellite companies offer identical products at identical prices across all geographic markets. Because of this, a profit-maximizing monopolist has, relative to the social planner, an incentive to provide higher-quality products similar to those of the satellite competitor at lower prices without fearing reprisals from the satellite company. ${ }^{38}$ However, providing products comparable in quality to high-end satellite products requires a high level of cost-efficiency; therefore not all cable firms will engage in it; only more cost-efficient ones will. Our cost estimates, illustrated in Figure 3, show that two- and three-product cable systems tend to be more cost efficient than one-product providers. Hence, we would expect

\footnotetext{
${ }^{38}$ Indeed, when one of the 11,000 local cable firm changes its policy it is very unlikely that satellite competitors will respond by changing their national prices and quality levels in response.
} 
Panel A. With DBS competitor

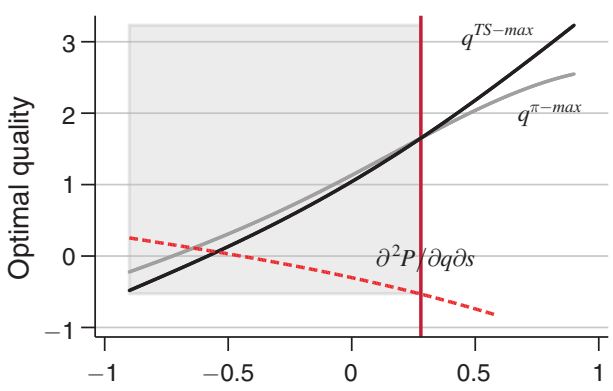

Correlation coefficient, $\rho\left(\alpha_{i p}, \alpha_{i q}\right)$
Panel B. Without DBS competitor

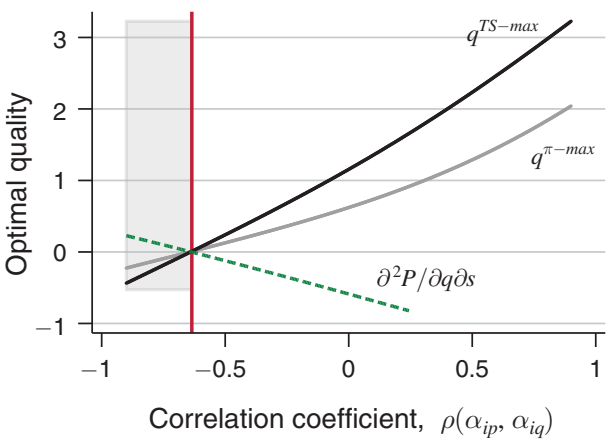

FIGURE 6

Notes: Single-product market (Austin, TX): profit and TS maximizing cable quality for monopolist with (panel A) and without (panel B) the presence of a DBS competitor. Shaded area to the left of the red line describes the range of parameter values where a profit-maximizing firm would overprovide quality relative to the first best.

a higher preponderance of quality overprovision in multi-product markets, which is precisely what we find in Figure 4: cable quality is typically overprovided in multi-product markets but underprovided in single-product markets. ${ }^{39}$

While we have focused here on quality overprovision in multi-good markets, the theory in Spence (1975) shows that quality overprovision can also arise in single-good monopoly markets. We conclude this section by testing Spence's results. While Figure 4 shows that there are not many single-product markets in which quality overprovision is present, we consider one such market (Austin, TX) in which overprovision does occur. Figure 6 is analogous to Figure 5, and shows that, similarly to the previous results, when we take away satellite competition, then the quality overprovision result essentially disappears. 40

To consider whether Spence's results are relevant here, we use Proposition 1 from Spence (1975), which states that for a single-product monopolist a sufficient condition for quality underprovision is that $\partial^{2} P / \partial q \partial s<0$, i.e., that the cross-partial of the inverse demand function with respect to quality and quantity is negative. For our demand model, we used the implicit function theorem to compute this cross-partial derivative for different values of the correlation coefficient as plotted in Figure 6.

Interestingly, in the absence of DBS competition (panel B) we see that the value of $\partial P / \partial q \partial s$ is positive (green dash line) when the monopolist overprovides quality and negative when the monopolist underprovides quality, which is exactly in line with the Spence model. In the presence of DBS competition, however, Spence's proposition no longer holds, and we see from panel A that in this case a profit-maximizing monopolist would choose to overprovide quality for a wide range of values of $\rho$ even when the cross-partial is negative.

\footnotetext{
${ }^{39}$ Out of 7,100 one-product market observations, we found that cable firms overprovide quality in only about 20 percent. The overprovision result is much stronger in two- and three- product markets, where quality is inflated in 85 percent and 95 percent of observations, respectively.

${ }^{40}$ Appendix Section AE provides similar simulations for four additional markets, which show the robustness of the conclusions in this section across different values of $\rho$.
} 
Panel A. 1-product markets

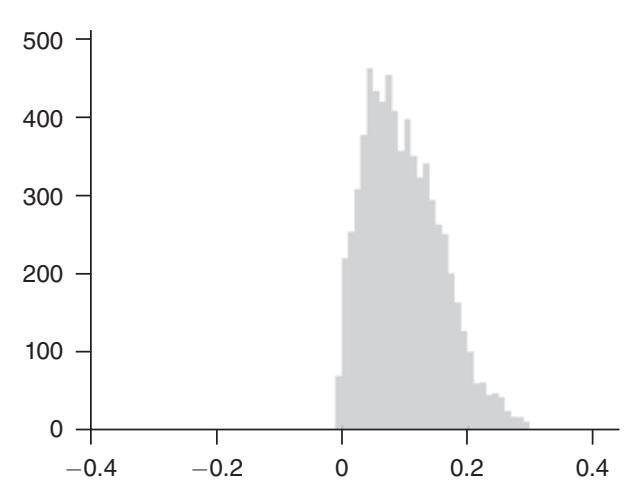

Panel B. 2-product markets

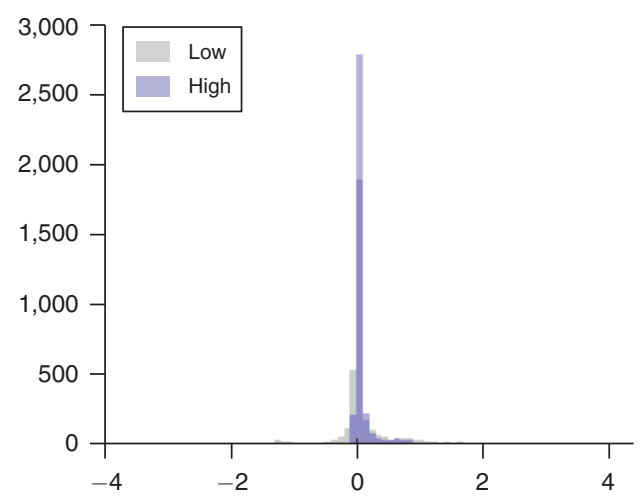

Panel C. 3-product markets

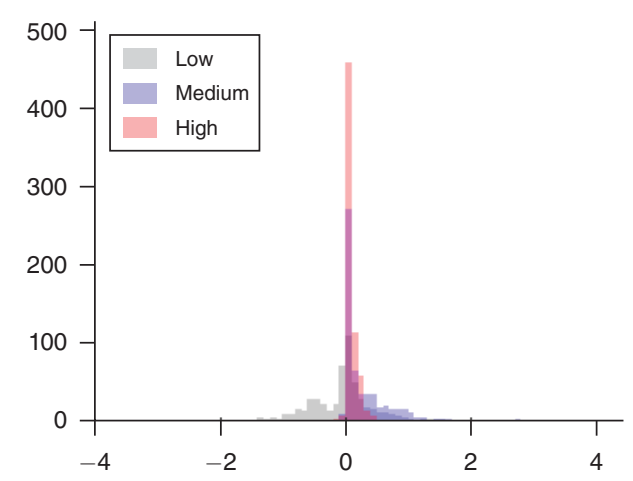

Figure 7. Quality Inflation for Each Product by Type of Cable System: Socially Optimal and Profit Maximizing If DBS Is Out

Note: Quality inflation is defined in percentage terms as the difference between socially optimal and profit-maximizing quality level when DBS is eliminated from the market.

While the results to this point have discussed specific individual markets, they are robust across the markets in our sample. Specifically, Figure 7 reports $\left(q^{T S-\max }-q^{\pi-\max }\right) / q^{\pi-\max }$, the percentage difference between socially-optimal and profit-maximizing quality levels when DBS is absent across all the markets in our data. ${ }^{41}$

The results clearly demonstrate the robustness of our result that quality overprovision only occurs in the presence of a DBS competitor. We see that for all 1-, 2-, and 3-product markets, the mass of the histograms are primarily in the positive region, indicating that firms would engage in quality degradation (i.e., setting profit-maximizing qualities lower than socially optimal) in the absence of DBS competition. This is a dramatic difference compared to the widespread evidence of quality overprovision in the presence of DBS competition shown in Figure 4.

\footnotetext{
${ }^{41}$ Note that both of these are counterfactual qualities, which are simulated from the structural model.
} 
To sum up, our explorations in this section have shown that the quality overprovision which we have documented in cable TV markets appears to arise from cable companies' efforts to compete effectively with a high-end outside option (satellite TV); this is consistent with the theoretical results in Champsaur and Rochet (1989). Moreover, even in single-good markets, our results confirm Spence's (1975) finding that the monopolist can over- or underprovide quality depending on the curvature of the inverse demand function. These results are robust across values of the $\rho$ parameter, which suggests that the quality overprovision result is not merely a function of the estimated correlation in preferences for price and quality, but depends critically on the presence and nature of competition with high-quality (satellite) competitors.

\section{Conclusions}

In this paper, we develop a model of consumer and producer behavior to measure the distortions in product quality in imperfectly competitive markets for paid television services. We estimate demand- and supply-side structural parameters using data from the US local cable markets in 1997-2006. Via counterfactual simulations, we find that cable companies set both prices and qualities too high relative to the social optimum: qualities between 23 percent and 55 percent and prices between 33 percent and 74 percent. Cable customers are facing overly large bundles at inflated prices, and would prefer smaller bundles with lower prices. These are important insights into how consumers trade off price versus quality and may be particularly relevant to US policymakers concerned about high and rising pay television prices.

Our finding that a monopolist can overprovide quality is novel relative to the existing empirical literature. Further investigations show that this result is driven by the presence of a high-end outside option represented by satellite products, thus providing empirical support for the theoretical results in Champsaur and Rochet (1989).

Our results point the way to several possible extensions. Based on features of the institutional environment, we take the number of products offered by firms as fixed. We assume consumers have preferences over a scalar "quality" variable, and extending our framework to allow for heterogeneous tastes across multiple different television networks would be useful. Consumer demand in television markets can exhibit dynamic features, such as state dependence or switching costs, and extending our analysis to examine firms' quality choices under richer demand specifications would be fruitful. ${ }^{42}$ Finally, we focus on the quality (and price) choices of downstream distributors, taking as given the qualities of upstream television networks; generalizing the analysis to those firms' quality choices would also be of interest.

\section{Appendix A. Additional Results}

\section{A. Additional Reduced-Form Evidence of Quality Inflation}

Here we present some additional reduced-form evidence regarding the extent of quality overprovision by cable monopolists facing satellite competition. Table 8

\footnotetext{
${ }^{42}$ Shcherbakov (2016) estimates a dynamic demand model for television markets.
} 
Table 8-Cable Quality Changes around Local Channels Intro by DBS

\begin{tabular}{|c|c|c|c|c|c|c|}
\hline & \multirow{2}{*}{$\frac{1 \text {-product }}{q}$} & \multicolumn{2}{|c|}{ 2-product } & \multicolumn{3}{|c|}{ 3-product } \\
\hline & & $q_{\text {low }}$ & $q_{\text {high }}$ & $q_{\text {low }}$ & $q_{\text {med }}$ & $q_{\text {high }}$ \\
\hline Intro year +2 and after & $\begin{array}{c}0.089 \\
(0.098)\end{array}$ & $\begin{array}{c}0.265 \\
(0.078)\end{array}$ & $\begin{array}{c}0.405 \\
(0.089)\end{array}$ & $\begin{array}{c}0.452 \\
(0.108)\end{array}$ & $\begin{array}{c}0.587 \\
(0.143)\end{array}$ & $\begin{array}{c}0.762 \\
(0.160)\end{array}$ \\
\hline Intro year +1 & $\begin{array}{c}0.207 \\
(0.101)\end{array}$ & $\begin{array}{c}0.203 \\
(0.156)\end{array}$ & $\begin{array}{c}0.193 \\
(0.180)\end{array}$ & $\begin{array}{l}-0.207 \\
(0.247)\end{array}$ & $\begin{array}{l}-0.348 \\
(0.326)\end{array}$ & $\begin{array}{l}-0.328 \\
(0.364)\end{array}$ \\
\hline Intro year & $\begin{array}{l}-0.040 \\
(0.082)\end{array}$ & $\begin{array}{c}0.138 \\
(0.130)\end{array}$ & $\begin{array}{c}0.344 \\
(0.150)\end{array}$ & $\begin{array}{c}0.263 \\
(0.210)\end{array}$ & $\begin{array}{c}0.298 \\
(0.278)\end{array}$ & $\begin{array}{c}0.521 \\
(0.310)\end{array}$ \\
\hline Intro year - 1 & $\begin{array}{c}0.157 \\
(0.069)\end{array}$ & $\begin{array}{c}0.037 \\
(0.095)\end{array}$ & $\begin{array}{c}0.047 \\
(0.110)\end{array}$ & $\begin{array}{c}0.185 \\
(0.171)\end{array}$ & $\begin{array}{c}0.041 \\
(0.226)\end{array}$ & $\begin{array}{l}-0.044 \\
(0.252)\end{array}$ \\
\hline Intro year - 2 & $\begin{array}{c}0.144 \\
(0.056)\end{array}$ & $\begin{array}{c}0.257 \\
(0.101)\end{array}$ & $\begin{array}{c}0.194 \\
(0.116)\end{array}$ & $\begin{array}{l}-0.300 \\
(0.242)\end{array}$ & $\begin{array}{l}-0.090 \\
(0.319)\end{array}$ & $\begin{array}{l}-0.163 \\
(0.356)\end{array}$ \\
\hline Constant & $\begin{array}{c}2.481 \\
(0.029)\end{array}$ & $\begin{array}{c}1.351 \\
(0.051)\end{array}$ & $\begin{array}{c}3.405 \\
(0.058)\end{array}$ & $\begin{array}{c}1.930 \\
(0.114)\end{array}$ & $\begin{array}{c}2.961 \\
(0.150)\end{array}$ & $\begin{array}{c}4.868 \\
(0.168)\end{array}$ \\
\hline Year dummy variables & Yes & Yes & Yes & Yes & Yes & Yes \\
\hline $\begin{array}{l}\text { Observations } \\
R^{2}\end{array}$ & $\begin{array}{l}7,140 \\
0.191\end{array}$ & $\begin{array}{l}3,693 \\
0.625\end{array}$ & $\begin{array}{l}3,693 \\
0,341\end{array}$ & $\begin{array}{l}1,381 \\
0157\end{array}$ & $\begin{array}{l}1,381 \\
0.576\end{array}$ & $\begin{array}{l}1,381 \\
0554\end{array}$ \\
\hline$R^{2}$ & 0.191 & 0.625 & 0.341 & 0.157 & 0.576 & 0.554 \\
\hline
\end{tabular}

Note: Standard errors in parentheses.

presents regressions in which the dependent variable is the quality level for each of the available product tiers. The key independent variables are dummy variables for years before and after the year in which the cable system's DBS competitor begins carrying local channels.

While not all the parameters on these dummy variables are precisely estimated, we find that statistically significant post-intro coefficients are all positive, which we expect if cable firms inflate quality when facing a more competitive high-end alternative. Interestingly, in multi-product markets, the coefficients in the post-intro dummies are larger in magnitude for higher-quality products, which is consistent with our structural estimates from Section V.

\section{B. Surplus and Buying Probabilities across Consumer Types}

Purchase Probabilities.-We created heat map graphs for representative 1- and 2-product markets, discussed in Section VI. Taking satellite TV as the highest quality product, we see that consumers who have the highest probability of buying satellite (i.e., the yellow blocks in panel B of both Figures 8 and 9) are primarily those with intermediate values for the quality coefficient. In comparison, consumers with high-quality coefficients are most likely to buy lower-quality cable products, as shown in panel A in Figures 8 and 9.

Consumers Surplus.-To illustrate the type-specific surplus distribution in our multi-dimensional model, we created surface graphs measuring expected consumer surplus in dollar equivalent as a function of the heterogeneity parameters $\alpha_{i p}$ and $\alpha_{i q}$ (price and quality sensitivity, respectively). Figure 10 illustrates consumer surplus distribution for the same 1- and 2-product markets we used for analysis in Section VI. 
Panel A. Heat map for $\operatorname{Pr}($ buy CAB)

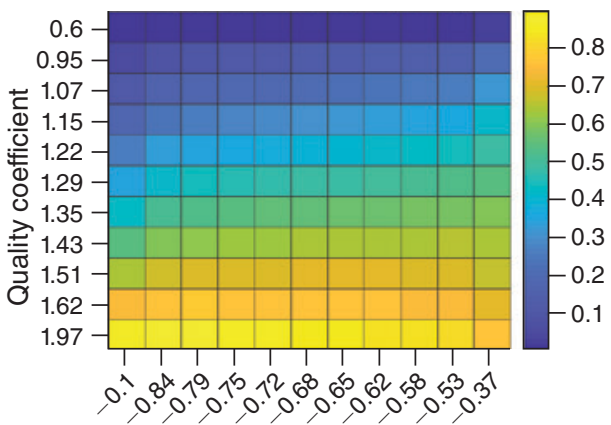

Price coefficient
Panel B. Heat map for $\operatorname{Pr}($ buy SAT)

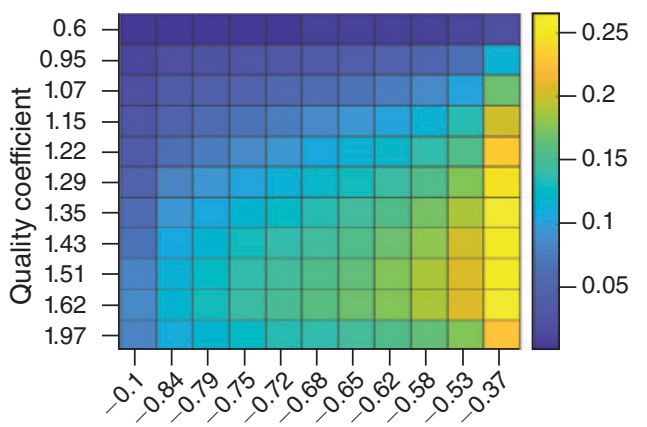

Price coefficient

Figure 8. Heat Map and Surface for Probability of Buying Cable and DBS, 2-Product Market

Panel A. Heat map for $\operatorname{Pr}($ buy CAB)

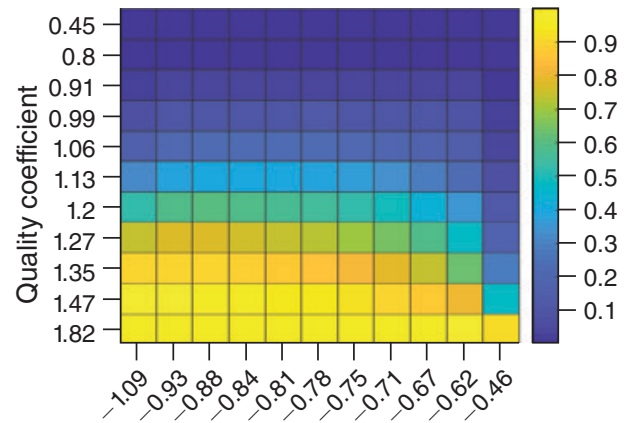

Price coefficient
Panel B. Heat map for $\operatorname{Pr}($ buy SAT)

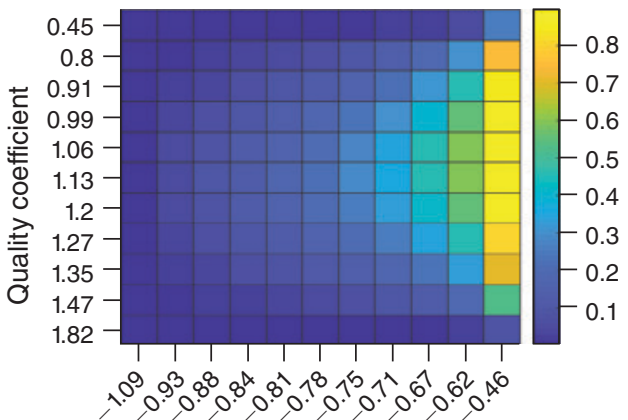

Price coefficient

Figure 9. Heat Map and Surface for Probability of Buying Cable and DBS, 1-Product Market

Panel A. 1-product market

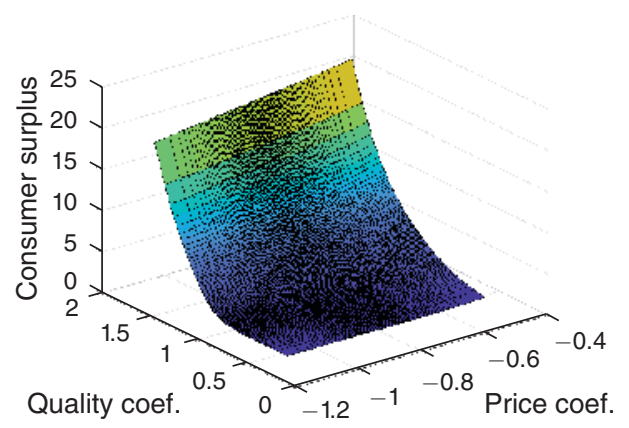

Panel B. 2-product market

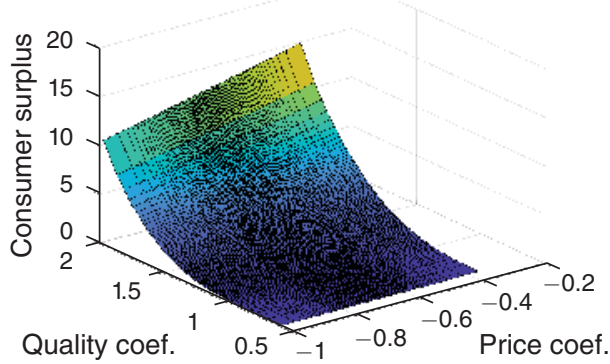

Figure 10. Distribution of Consumer Surplus in 1- AND 2-Product Markets

In these figures we see that generally, consumers with high WTP for quality and low price sensitivity gain the highest consumer surplus (shown as bright yellow in the graphs), while those with low WTP for quality obtain low consumer surplus, regardless of price sensitivity (shown as dark blue/purple). The latter result is 

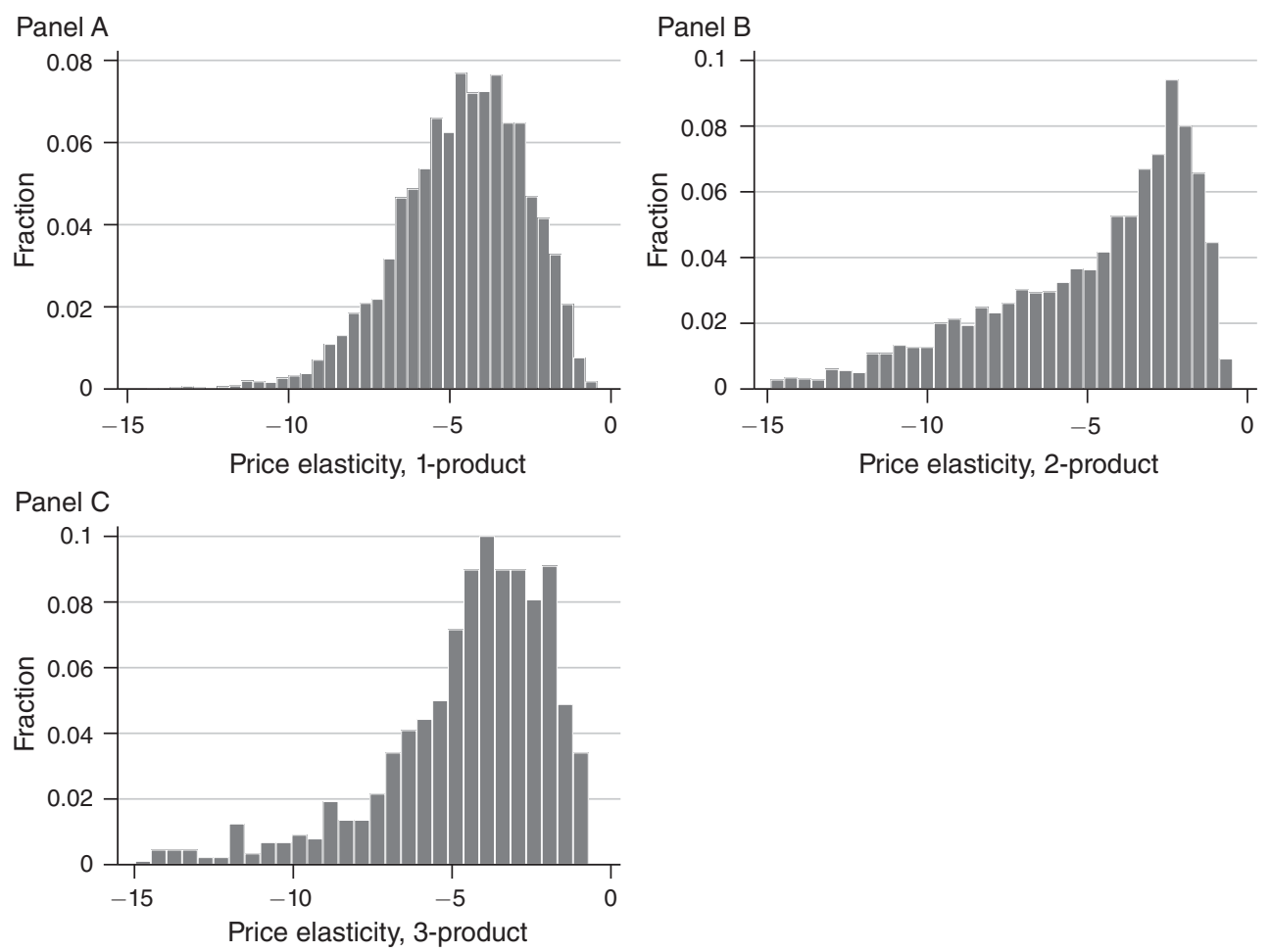

Figure 11. Histogram for Average Price Elasticities

Note: Three graphs show, respectively, distributions of weighted own price elasticities across markets with 1,2 , or 3 products.

perhaps not surprising, as consumers with low WTP for quality purchase the lowend outside option, and obtain low surplus.

\section{Price Elasticity and Markups}

\section{Details: Factual and Counterfactual Price and Quality Levels}

Table 11 provides the full set of prices and qualities underlying the results presented in Table 7 in the main text.

\section{E. Additional Simulations of Quality Distortions with and without DBS Competitor}

In this section, we have computed the profit-maximizing and social-optimal levels of quality across different values of the correlation parameter $\rho$, for several additional markets. They are shown in Figure 12. We computed the figures for two additional 1-product markets and two additional 2-product markets. For these markets, we don't always see quality overprovision: in observation 6,274 and 7,233, for instance, there is always quality degradation, both when DBS is present or absent. But in both cases, quality degradation is larger when DBS is absent, which is the 
Table 9-Summary Statistics for Weighted Average Own Price Elasticity by Product TyPe aCross MARKETS

\begin{tabular}{lccccc}
\hline \hline & Mean & Median & Min & Max & SD \\
\hline 1-product markets & -5.15 & -4.50 & -100.72 & -0.43 & 5.62 \\
2-product markets & -5.26 & -4.06 & -67.70 & -0.45 & 4.27 \\
3-product markets & -5.28 & -4.06 & -66.61 & -0.70 & 5.43 \\
\hline
\end{tabular}

Notes: To calculate the statistics for multi-product cable systems, we use product-specific market shares as the weights.

Table 10-Estimated Price Markups

\begin{tabular}{lcccc}
\hline \hline & & \multicolumn{2}{c}{ Price markups } \\
\cline { 3 - 5 } & Observations & Mean & SD \\
\hline 1-product markets & 7,105 & 0.264 & 0.139 \\
& & & \\
2-product markets & & & & \\
Low-quality products & 3,615 & 0.320 & 0.202 \\
High-quality products & 3,615 & 0.226 & 0.100 \\
& & & \\
3-product markets & & & \\
Low-quality products & 1,327 & 0.339 & 0.188 \\
Medium-quality products & 1,327 & 0.174 & 0.101 \\
High-quality products & 1,327 & 0.210 & 0.095 \\
\hline
\end{tabular}

Notes: Reported are estimated price markups from our baseline estimation results (Table 5, column 2). Price markups are reported as a percentage of price, $\left(p_{j}-m c_{j}\right) / p_{j}$. Estimated values are averaged across markets by market type (1-, 2-, or 3-product markets) and product type within market type.

Table 11-Factual and Counterfactual Levels of Price and Quality

\begin{tabular}{lcccc}
\hline \hline & $\left(p^{o}, q^{o}\right)$ & $\left(p^{s}, q^{o}\right)$ & $\left(p^{o}, q^{s}\right)$ & $\left(p^{s}, q^{s}\right)$ \\
\hline 1-product & & & & \\
$p_{\text {low }}$ & 22.34 & 16.81 & 22.34 & 17.14 \\
$q_{\text {low }}$ & 3.26 & 3.26 & 4.70 & 3.44 \\
& & & & \\
2-product & & & & \\
$p_{\text {low }}$ & 18.08 & 13.44 & 18.08 & 10.91 \\
$q_{\text {low }}$ & 3.07 & 3.07 & 3.46 & 1.57 \\
$p_{\text {high }}$ & 33.30 & 26.05 & 33.30 & 14.40 \\
$q_{\text {high }}$ & 5.25 & 5.25 & 5.69 & 3.54 \\
3-product & & & & \\
$p_{\text {low }}$ & & & & \\
$q_{\text {low }}$ & 18.19 & 12.85 & 18.19 & 10.08 \\
$p_{\text {med }}$ & 2.55 & 2.55 & 3.35 & 0.90 \\
$q_{\text {med }}$ & 33.85 & 28.61 & 33.85 & 12.99 \\
$p_{\text {high }}$ & 7.36 & 7.36 & 7.66 & 2.74 \\
$q_{\text {high }}$ & 61.00 & 47.82 & 61.00 & 15.29 \\
\hline & 9.13 & 9.13 & 9.71 & 3.88 \\
\hline
\end{tabular}

direction that we would expect. The other two markets present results qualitatively similar to those presented in Section VI. Despite their slight differences, the main point of these additional simulations is that the primary conclusions of the paper are robust across different values of $\rho$. 
Panel A. 1-product market: 6,274 observations (Peducah-Cape Girardeau-Harrisburg, MO, 2001) With DBS competitor

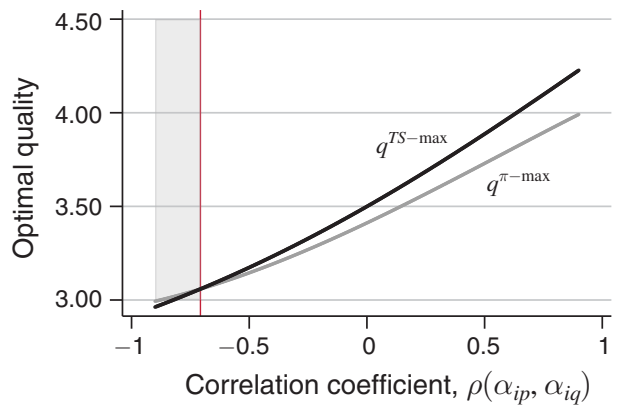

Without DBS competitor

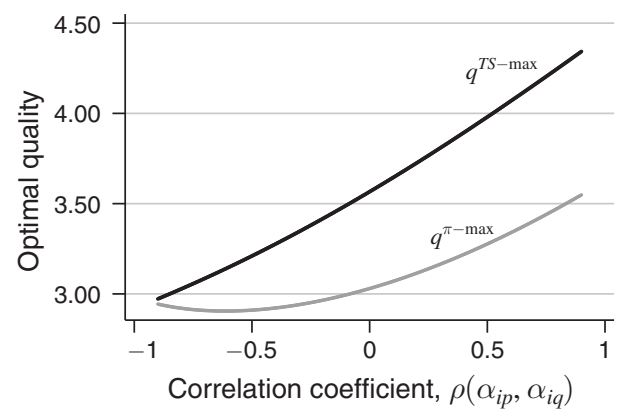

Panel B. 1-product market: 8,749 observations (Cincinnati, $\mathrm{OH}, 2002$ )

With DBS competitor

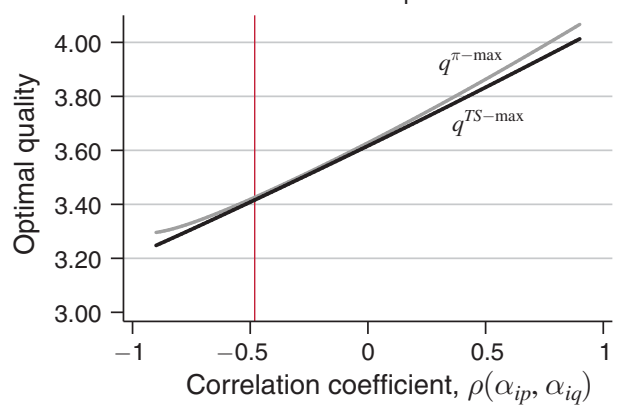

Without DBS competitor

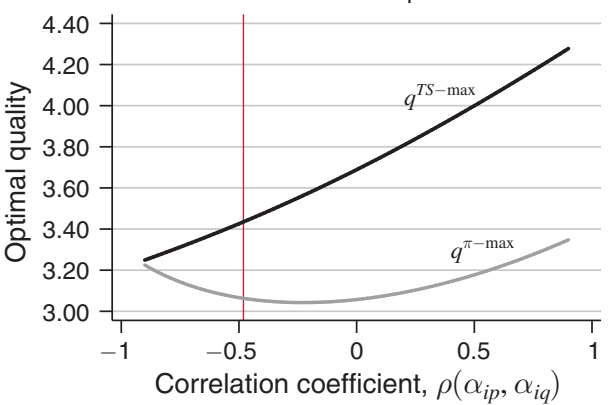

Panel C. 2-product market: 7,233 observations (Greenville-New Bern-Washington, NC, 2002)
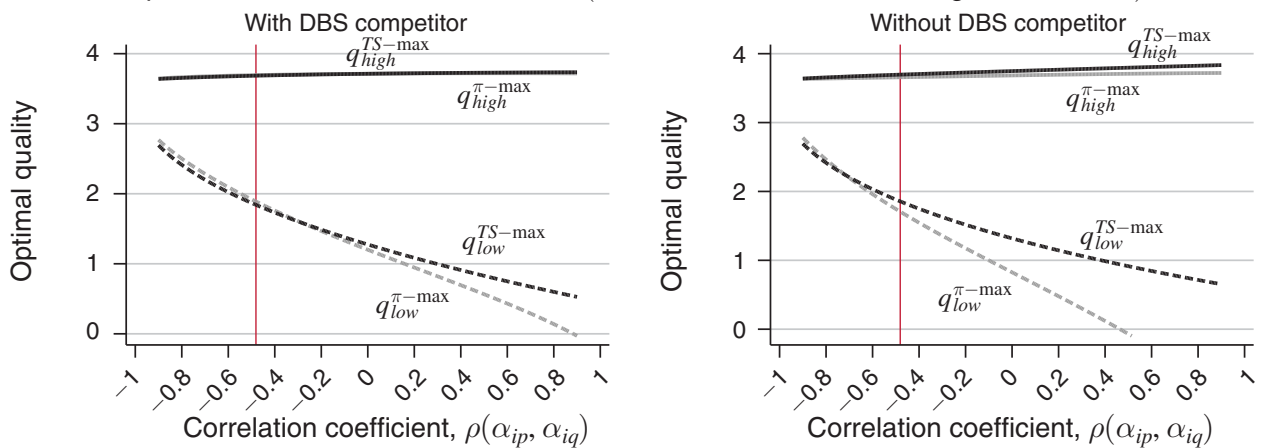

Panel D. 2-product market: 1,000 observations (Medford-Klamath Falls, CA, 1997)
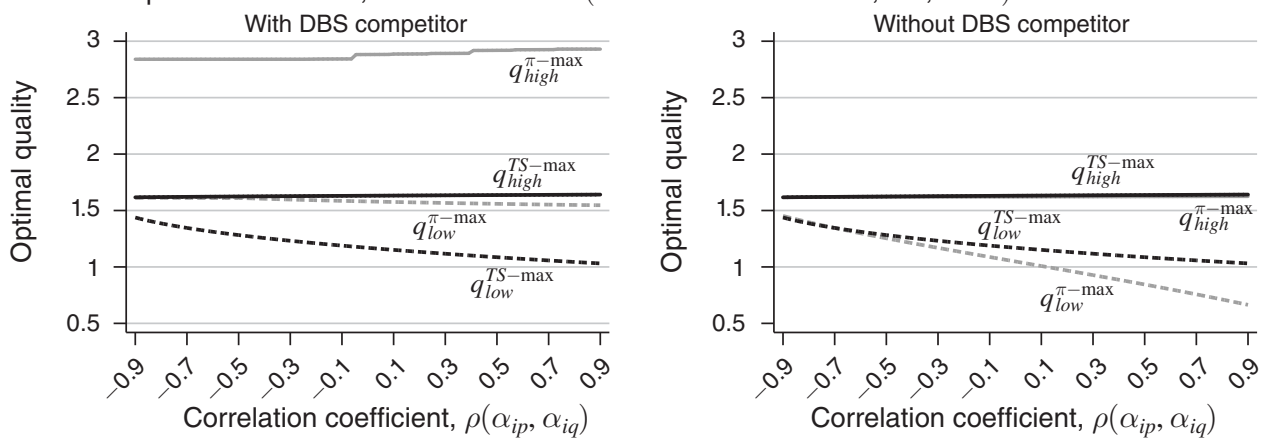

Figure 12. Additional Robustness Checks on Correlation Parameter $\rho$ 


\section{Appendix B. Robustness Checks}

\section{A. Alternative Sets of Instrumental Variables}

Table 12 reports parameter estimates for two alternative specifications (both GMM second stage). The first one is OLS-type where price and quality variables were used as own instruments. In order to identify parameters of consumer heterogeneity, we used additional instruments such as MSO-based average quality and average price for each product.

To obtain estimates for the second specification, min-IV, we used a minimal set of instrumental variables (only ownership-based instruments were employed). OLStype specification results in smaller magnitudes for the price coefficients, similarly to the attenuation bias one would expect in a linear model. Estimation results from the min-IV specification turn out to be quite similar to the ones reported in the main text.

\section{B. Alternative Measures of Quality}

We provide comparison of estimation results under our original and two alternative measures of quality in Table 13. In particular, column 1 reproduces the results of our original specification. Column 2 assigns weight of 0 to any free-of-charge channel, i.e., measures quality as the total cost of nonfree channels in a bundle. Finally, column 3 assigns weight of 0.1 to each channel in the bundle. ${ }^{43}$ As the results indicate, the results are quantitatively and qualitatively robust across these alternative measures of quality.

\footnotetext{
${ }^{43}$ We chose this weight to obtain levels of quality that are roughly similar to our original measure.
} 
Table 12-Results for Alternative Specifications, 1997-2006 (12,214 Observations)

\begin{tabular}{lccccc}
\hline \hline & \multicolumn{2}{c}{ OLS-type } & & \multicolumn{2}{c}{ Min-IV } \\
\cline { 2 - 3 } Parameter & Coefficient & SE & & Coefficient & SE \\
\hline Price coefficient, $\alpha_{i p}$ & & & & & \\
Mean & -0.553 & $(0.000)$ & & -0.684 & $(0.011)$ \\
Income & -0.304 & $(0.027)$ & & -0.433 & $(0.022)$ \\
Household size & 0.190 & $(0.017)$ & & 0.415 & $(0.054)$ \\
Urban & -0.161 & $(0.029)$ & & -0.184 & $(0.036)$ \\
Sigma & 0.100 & $(0.003)$ & & 0.119 & $(0.011)$ \\
& & & & \\
Quality coefficient, $\alpha_{i q}$ & 1.105 & $(0.041)$ & & 1.228 & $(0.092)$ \\
Mean & -0.265 & $(0.265)$ & & -0.336 & $(0.807)$ \\
Income & 0.459 & $(0.200)$ & & 0.227 & $(0.387)$ \\
Household size & -0.003 & $(0.276)$ & & 0.334 & $(0.888)$ \\
Urban & 0.352 & $(0.003)$ & & 0.268 & $(0.011)$ \\
Sigma & & & & & \\
& -0.669 & $(0.010)$ & & -0.451 & $(0.013)$ \\
$\rho_{a b}$ & Yes & & & Yes & \\
Demand $t$-dummies & Yes & & & Yes & \\
Supply $t$-dummies & & & & &
\end{tabular}

Note: Full estimation results are available from the authors upon request.

Table 13-Robustness Checks for Alternative Measures of Quality

\begin{tabular}{|c|c|c|c|}
\hline Parameter & $\begin{array}{l}\text { Original } \\
\text { (1) }\end{array}$ & $\begin{array}{l}\text { Nonfree only } \\
\text { (2) }\end{array}$ & $\begin{array}{c}\text { Number of channels } \\
\text { (3) }\end{array}$ \\
\hline $\begin{array}{l}\text { Mean } \\
\quad \text { (Standard error) }\end{array}$ & $\begin{array}{l}-0.673 \\
(0.008)\end{array}$ & $\begin{array}{l}-0.727 \\
(0.047)\end{array}$ & $\begin{array}{l}-0.720 \\
(0.031)\end{array}$ \\
\hline $\begin{array}{l}\text { Sigma } \\
\text { (Standard error) }\end{array}$ & $\begin{array}{c}0.102 \\
(0.018)\end{array}$ & $\begin{array}{c}0.135 \\
(0.030)\end{array}$ & $\begin{array}{c}0.128 \\
(0.033)\end{array}$ \\
\hline $\begin{array}{l}\text { Quality coefficient, } \alpha_{i} \\
\text { Mean } \\
\quad \text { (Standard error) }\end{array}$ & $\begin{array}{l}1.108 \\
(0.121)\end{array}$ & $\begin{array}{l}1.265 \\
(0.110)\end{array}$ & $\begin{array}{c}0.881 \\
(0.180)\end{array}$ \\
\hline $\begin{array}{l}\text { Sigma } \\
\text { (Standard error) }\end{array}$ & $\begin{array}{c}0.310 \\
(0.020)\end{array}$ & $\begin{array}{c}0.368 \\
(0.087)\end{array}$ & $\begin{array}{c}0.391 \\
(0.081)\end{array}$ \\
\hline$\rho_{a b}($ Standard error $)$ & $\begin{array}{l}-0.545 \\
(0.128)\end{array}$ & $\begin{array}{l}-0.333 \\
(0.326)\end{array}$ & $\begin{array}{l}-0.351 \\
(0.313)\end{array}$ \\
\hline Demand $t$-dummies & Yes & Yes & Yes \\
\hline Supply $t$-dummies & Yes & Yes & Yes \\
\hline
\end{tabular}


Appendix C. Full Estimation Results

Table 14-Estimation Results, 1997-2006 (ObServations 12,214)

\begin{tabular}{|c|c|c|c|c|}
\hline \multirow[b]{2}{*}{ Parameter } & Coefficient & SE & Coefficient & SE \\
\hline & \multicolumn{2}{|c|}{$(1)$} & \multicolumn{2}{|c|}{$(2)$} \\
\hline \multicolumn{5}{|l|}{ Price coefficient, $\alpha_{i p}$} \\
\hline Mean & -0.673 & $(0.008)$ & -0.682 & $(0.035)$ \\
\hline Income & & & -0.418 & $(0.147)$ \\
\hline Household size & & & 0.396 & $(0.271)$ \\
\hline Urban & & & -0.173 & $(0.177)$ \\
\hline Sigma & 0.102 & $(0.018)$ & 0.122 & $(0.018)$ \\
\hline \multicolumn{5}{|c|}{ Quality coefficient, $\alpha_{i q}$} \\
\hline Mean & 1.108 & $(0.121)$ & 1.225 & $(0.241)$ \\
\hline Income & & & -0.337 & $(0.777)$ \\
\hline Household size & & & 0.221 & $(1.395)$ \\
\hline Urban & & & 0.331 & $(0.917)$ \\
\hline Sigma & 0.310 & $(0.020)$ & 0.266 & $(0.048)$ \\
\hline $\operatorname{corr}\left(a_{i p}, a_{i q}\right)$ & -0.545 & $(0.128)$ & -0.481 & $(0.049)$ \\
\hline \multicolumn{5}{|c|}{ Demand cab t-dummies } \\
\hline Const. & 10.313 & $(0.349)$ & 10.218 & $(0.479)$ \\
\hline$y-1998$ & 0.650 & $(0.259)$ & 0.590 & $(0.266)$ \\
\hline$y-1999$ & 2.022 & $(0.288)$ & 1.879 & $(0.305)$ \\
\hline$y-2000$ & 1.961 & $(0.327)$ & 1.815 & $(0.346)$ \\
\hline$y-2001$ & 1.607 & $(0.366)$ & 1.415 & $(0.384)$ \\
\hline$y-2002$ & -0.294 & $(0.397)$ & -0.415 & $(0.671)$ \\
\hline$y-2003$ & 1.976 & $(0.473)$ & 2.038 & $(0.584)$ \\
\hline$y-2004$ & 2.596 & $(0.720)$ & 2.631 & $(0.808)$ \\
\hline$y-2005$ & 0.243 & $(1.302)$ & 0.040 & $(1.369)$ \\
\hline$y-2006$ & 1.165 & $(0.704)$ & 1.002 & $(0.809)$ \\
\hline \multicolumn{5}{|c|}{ Demand sat $t$-dummies } \\
\hline Const. & 5.994 & $(0.301)$ & 5.915 & $(0.418)$ \\
\hline$y-1998$ & 0.351 & $(0.057)$ & 0.339 & $(0.072)$ \\
\hline$y-1999$ & 1.072 & $(0.062)$ & 1.062 & $(0.134)$ \\
\hline$y-2000$ & 0.016 & $(0.536)$ & -0.581 & $(0.629)$ \\
\hline$y-2001$ & 0.273 & $(0.496)$ & -0.354 & $(0.575)$ \\
\hline$y-2002$ & 2.698 & $(0.825)$ & 1.773 & $(0.993)$ \\
\hline$y-2003$ & 9.980 & $(0.883)$ & 9.172 & $(0.979)$ \\
\hline$y-2004$ & 7.866 & $(1.047)$ & 6.935 & (1.174) \\
\hline$y-2005$ & 7.043 & $(1.139)$ & 5.690 & $(1.277)$ \\
\hline$y-2006$ & 6.364 & $(1.169)$ & 5.101 & $(1.342)$ \\
\hline
\end{tabular}


Table 14-Estimation Results, 1997-2006 (Observations 12,214) (continued)

\begin{tabular}{|c|c|c|c|c|}
\hline \multirow[b]{2}{*}{ Parameter } & Coefficient & SE & Coefficient & SE \\
\hline & \multicolumn{2}{|c|}{ (1) } & \multicolumn{2}{|c|}{ (2) } \\
\hline \multicolumn{5}{|l|}{ Supply parameters, $c_{0 j}$} \\
\hline Const. & 1.779 & $(1.280)$ & 0.960 & (1.497) \\
\hline$y-1998$ & 0.017 & $(0.260)$ & -0.132 & $(0.303)$ \\
\hline$y-1999$ & -0.313 & $(1.338)$ & -0.049 & $(0.304)$ \\
\hline$y-2000$ & 0.051 & $(0.344)$ & 0.071 & $(0.223)$ \\
\hline$y-2001$ & 0.131 & $(0.361)$ & 0.109 & $(0.207)$ \\
\hline$y-2002$ & -1.952 & $(3.218)$ & -0.917 & (1.991) \\
\hline$y-2003$ & -0.535 & $(0.869)$ & -0.575 & $(0.655)$ \\
\hline$y-2004$ & 0.078 & $(0.647)$ & 0.089 & $(0.566)$ \\
\hline$y-2005$ & -0.219 & $(1.385)$ & -0.158 & (1.119) \\
\hline$y-2006$ & -0.204 & $(0.809)$ & -0.110 & $(0.563)$ \\
\hline $\mathrm{MSO}_{\left(p_{0}\right)}$ & 0.448 & $(0.337)$ & 0.568 & $(0.204)$ \\
\hline $\operatorname{MSO}_{\left(p_{1}\right)}^{\left(p_{0}\right)}$ & -0.696 & $(0.587)$ & -0.648 & $(0.254)$ \\
\hline $\operatorname{MSO}_{\left(p_{2}\right)}$ & 0.454 & $(0.629)$ & 0.195 & $(0.312)$ \\
\hline $\operatorname{MSO}_{\left(q_{0}\right)}$ & -0.651 & $(4.754)$ & 0.245 & $(4.096)$ \\
\hline $\operatorname{MSO}_{\left(q_{1}\right)}$ & 0.717 & $(2.810)$ & 0.146 & $(1.248)$ \\
\hline $\operatorname{MSO}_{\left(q_{2}\right)}$ & -2.528 & $(7.490)$ & 0.147 & (3.287) \\
\hline MSO sub. & 0.000 & $(0.000)$ & 0.000 & $(0.000)$ \\
\hline MSO cap. & 0.011 & $(0.030)$ & 0.015 & $(0.019)$ \\
\hline MSO num. prod. & -0.304 & $(0.435)$ & -0.234 & $(0.504)$ \\
\hline Own cap. & -0.002 & $(0.015)$ & 0.000 & $(0.005)$ \\
\hline Own m.coax. & -0.031 & $(0.360)$ & -0.017 & $(0.216)$ \\
\hline \multicolumn{5}{|c|}{ Supply parameters, $c_{1 j}$} \\
\hline Const. & 0.370 & $(1.236)$ & 0.523 & $(0.375)$ \\
\hline$y-1998$ & -0.044 & $(0.248)$ & 0.042 & $(0.102)$ \\
\hline$y-1999$ & 0.040 & $(0.223)$ & 0.011 & $(0.136)$ \\
\hline$y-2000$ & -0.015 & $(0.231)$ & -0.022 & $(0.055)$ \\
\hline$y-2001$ & -0.041 & $(0.136)$ & -0.032 & $(0.052)$ \\
\hline$y-2002$ & 1.085 & $(2.282)$ & 0.139 & $(0.349)$ \\
\hline$y-2003$ & 0.214 & $(0.633)$ & 0.103 & $(0.127)$ \\
\hline$y-2004$ & 0.100 & $(0.509)$ & -0.035 & $(0.105)$ \\
\hline$y-2005$ & 0.137 & $(0.923)$ & -0.013 & $(0.209)$ \\
\hline$y-2006$ & 0.048 & $(0.574)$ & -0.055 & $(0.094)$ \\
\hline $\operatorname{MSO}_{\left(p_{0}\right)}$ & 0.098 & $(0.800)$ & -0.082 & $(0.046)$ \\
\hline $\operatorname{MSO}_{\left(p_{1}\right)}^{\left(p_{0}\right)}$ & 0.286 & $(0.213)$ & 0.195 & $(0.073)$ \\
\hline $\operatorname{MSO}_{\left(p_{2}\right)}$ & -0.212 & $(0.341)$ & -0.026 & $(0.080)$ \\
\hline $\operatorname{MSO}_{\left(q_{0}\right)}$ & -1.339 & $(9.408)$ & -0.429 & (1.017) \\
\hline $\operatorname{MSO}_{\left(q_{1}\right)}$ & -0.365 & $(1.454)$ & 0.049 & $(0.326)$ \\
\hline $\operatorname{MSO}_{\left(q_{2}\right)}^{\left(q_{1}\right)}$ & 1.674 & $(2.824)$ & 0.016 & $(0.765)$ \\
\hline MSO sub. & -0.000 & $(0.000)$ & -0.000 & $(0.000)$ \\
\hline MSO cap. & -0.003 & $(0.013)$ & -0.003 & $(0.004)$ \\
\hline MSO num. prod. & -0.059 & $(0.383)$ & 0.006 & $(0.092)$ \\
\hline Own cap. & 0.000 & $(0.012)$ & -0.001 & $(0.001)$ \\
\hline Own m.coax. & 0.017 & $(0.253)$ & -0.001 & $(0.032)$ \\
\hline
\end{tabular}




\section{Appendix D. First-Stage Regressions}

TABLe 15-First-Stage Regressions

\begin{tabular}{|c|c|c|c|c|c|c|}
\hline Variables & $p_{c 0}$ & $p_{c 1}$ & $p_{c 2}$ & $q_{c 0}$ & $q_{c 1}$ & $q_{c 2}$ \\
\hline $\operatorname{MSO}_{\left(p_{0}\right)}$ & $\begin{array}{c}1.713 \\
(0.151)\end{array}$ & $\begin{array}{c}1.491 \\
(0.194)\end{array}$ & $\begin{array}{c}1.692 \\
(0.317)\end{array}$ & $\begin{array}{c}-0.905 \\
(0.0329)\end{array}$ & $\begin{array}{c}0.322 \\
(0.0357)\end{array}$ & $\begin{array}{c}0.610 \\
(0.0478)\end{array}$ \\
\hline $\operatorname{MSO}_{\left(p_{1}\right)}$ & $\begin{array}{l}-4.642 \\
(0.156)\end{array}$ & $\begin{array}{c}17.87 \\
(0.201)\end{array}$ & $\begin{array}{l}-9.870 \\
(0.327)\end{array}$ & $\begin{array}{c}-1.000 \\
(0.0339)\end{array}$ & $\begin{array}{c}1.870 \\
(0.0369)\end{array}$ & $\begin{array}{c}-1.711 \\
(0.0493)\end{array}$ \\
\hline $\operatorname{MSO}_{\left(p_{2}\right)}$ & $\begin{array}{c}2.623 \\
(0.201)\end{array}$ & $\begin{array}{c}0.515 \\
(0.258)\end{array}$ & $\begin{array}{c}20.49 \\
(0.421)\end{array}$ & $\begin{array}{c}0.0896 \\
(0.0437)\end{array}$ & $\begin{array}{c}-0.312 \\
(0.0475)\end{array}$ & $\begin{array}{c}2.268 \\
(0.0634)\end{array}$ \\
\hline $\operatorname{MSO}_{\left(q_{0}\right)}$ & $\begin{array}{c}25.06 \\
(2.749)\end{array}$ & $\begin{array}{l}-68.72 \\
(3.531)\end{array}$ & $\begin{array}{l}-10.98 \\
(5.757)\end{array}$ & $\begin{array}{c}11.72 \\
(0.597)\end{array}$ & $\begin{array}{l}-11.61 \\
(0.649)\end{array}$ & $\begin{array}{l}-6.745 \\
(0.867)\end{array}$ \\
\hline $\operatorname{MSO}_{\left(q_{1}\right)}$ & $\begin{array}{c}11.50 \\
(1.000)\end{array}$ & $\begin{array}{l}-17.67 \\
(1.285)\end{array}$ & $\begin{array}{l}-10.69 \\
(2.095)\end{array}$ & $\begin{array}{c}2.259 \\
(0.217)\end{array}$ & $\begin{array}{l}-3.172 \\
(0.236)\end{array}$ & $\begin{array}{l}-2.113 \\
(0.316)\end{array}$ \\
\hline $\operatorname{MSO}_{\left(q_{2}\right)}$ & $\begin{array}{l}-6.523 \\
(1.130)\end{array}$ & $\begin{array}{c}2.201 \\
(1.452)\end{array}$ & $\begin{array}{l}-44.70 \\
(2.367)\end{array}$ & $\begin{array}{l}-0.410 \\
(0.245)\end{array}$ & $\begin{array}{c}1.447 \\
(0.267)\end{array}$ & $\begin{array}{l}-5.210 \\
(0.357)\end{array}$ \\
\hline MSO sub & $\begin{array}{c}-0.000122 \\
(1.66 \mathrm{e}-05)\end{array}$ & $\begin{array}{c}0.000108 \\
(2.14 \mathrm{e}-05)\end{array}$ & $\begin{array}{c}0.000309 \\
(3.48 \mathrm{e}-05)\end{array}$ & $\begin{array}{l}-2.19 \mathrm{e}-05 \\
(3.61 \mathrm{e}-06)\end{array}$ & $\begin{array}{c}6.82 \mathrm{e}-05 \\
(3.93 \mathrm{e}-06)\end{array}$ & $\begin{array}{r}8.61 \mathrm{e}-05 \\
(5.25 \mathrm{e}-06)\end{array}$ \\
\hline MSO cap. & $\begin{array}{c}0.182 \\
(0.00914)\end{array}$ & $\begin{array}{c}0.135 \\
(0.0117)\end{array}$ & $\begin{array}{c}-0.135 \\
(0.0191)\end{array}$ & $\begin{array}{c}0.0328 \\
(0.00198)\end{array}$ & $\begin{array}{c}0.0128 \\
(0.00216)\end{array}$ & $\begin{array}{c}-0.0166 \\
(0.00288)\end{array}$ \\
\hline MSO num. prod. & $\begin{array}{l}-3.177 \\
(0.298)\end{array}$ & $\begin{array}{c}0.339 \\
(0.383)\end{array}$ & $\begin{array}{c}19.56 \\
(0.624)\end{array}$ & $\begin{array}{c}-0.523 \\
(0.0647)\end{array}$ & $\begin{array}{c}0.984 \\
(0.0703)\end{array}$ & $\begin{array}{c}2.556 \\
(0.0940)\end{array}$ \\
\hline Own cap. & $\begin{array}{c}0.00801 \\
(0.00378)\end{array}$ & $\begin{array}{c}0.0574 \\
(0.00486)\end{array}$ & $\begin{array}{c}0.163 \\
(0.00792)\end{array}$ & $\begin{array}{c}0.00560 \\
(0.000821)\end{array}$ & $\begin{array}{c}0.0244 \\
(0.000893)\end{array}$ & $\begin{array}{c}0.0249 \\
(0.00119)\end{array}$ \\
\hline Own cable len. & $\begin{array}{l}-0.648 \\
(0.116)\end{array}$ & $\begin{array}{c}1.382 \\
(0.149)\end{array}$ & $\begin{array}{c}5.129 \\
(0.242)\end{array}$ & $\begin{array}{c}-0.192 \\
(0.0251)\end{array}$ & $\begin{array}{c}0.481 \\
(0.0273)\end{array}$ & $\begin{array}{c}0.735 \\
(0.0365)\end{array}$ \\
\hline Constant & $\begin{array}{c}8.887 \\
(0.856)\end{array}$ & $\begin{array}{c}4.650 \\
(1.100)\end{array}$ & $\begin{array}{l}-21.70 \\
(1.792)\end{array}$ & $\begin{array}{c}0.916 \\
(0.186)\end{array}$ & $\begin{array}{l}-0.720 \\
(0.202)\end{array}$ & $\begin{array}{l}-2.677 \\
(0.270)\end{array}$ \\
\hline$t=1998$ & $\begin{array}{l}-0.260 \\
(0.203)\end{array}$ & $\begin{array}{c}0.810 \\
(0.261)\end{array}$ & $\begin{array}{c}0.841 \\
(0.425)\end{array}$ & $\begin{array}{c}-0.00559 \\
(0.0441)\end{array}$ & $\begin{array}{c}0.341 \\
(0.0479)\end{array}$ & $\begin{array}{c}0.247 \\
(0.0640)\end{array}$ \\
\hline$t=1999$ & $\begin{array}{c}1.450 \\
(0.212)\end{array}$ & $\begin{array}{c}1.272 \\
(0.273)\end{array}$ & $\begin{array}{c}0.911 \\
(0.445)\end{array}$ & $\begin{array}{c}0.341 \\
(0.0461)\end{array}$ & $\begin{array}{c}0.638 \\
(0.0501)\end{array}$ & $\begin{array}{c}0.362 \\
(0.0670)\end{array}$ \\
\hline$t=2000$ & $\begin{array}{c}0.955 \\
(0.243)\end{array}$ & $\begin{array}{c}3.000 \\
(0.312)\end{array}$ & $\begin{array}{c}1.440 \\
(0.508)\end{array}$ & $\begin{array}{c}0.259 \\
(0.0527)\end{array}$ & $\begin{array}{c}0.912 \\
(0.0573)\end{array}$ & $\begin{array}{c}0.447 \\
(0.0766)\end{array}$ \\
\hline$t=2001$ & $\begin{array}{c}1.025 \\
(0.257)\end{array}$ & $\begin{array}{c}3.404 \\
(0.331)\end{array}$ & $\begin{array}{c}2.314 \\
(0.539)\end{array}$ & $\begin{array}{c}0.221 \\
(0.0558)\end{array}$ & $\begin{array}{c}0.997 \\
(0.0607)\end{array}$ & $\begin{array}{c}0.549 \\
(0.0812)\end{array}$ \\
\hline$t=2002$ & $\begin{array}{l}-1.545 \\
(0.302)\end{array}$ & $\begin{array}{c}3.663 \\
(0.388)\end{array}$ & $\begin{array}{l}0.0802 \\
(0.632)\end{array}$ & $\begin{array}{c}0.265 \\
(0.0655)\end{array}$ & $\begin{array}{c}1.128 \\
(0.0712)\end{array}$ & $\begin{array}{c}0.391 \\
(0.0952)\end{array}$ \\
\hline$t=2003$ & $\begin{array}{c}7.517 \\
(0.361)\end{array}$ & $\begin{array}{c}16.30 \\
(0.464)\end{array}$ & $\begin{array}{l}-0.463 \\
(0.756)\end{array}$ & $\begin{array}{c}2.091 \\
(0.0783)\end{array}$ & $\begin{array}{c}2.932 \\
(0.0852)\end{array}$ & $\begin{array}{c}1.067 \\
(0.114)\end{array}$ \\
\hline$t=2004$ & $\begin{array}{c}9.301 \\
(0.460)\end{array}$ & $\begin{array}{c}20.47 \\
(0.591)\end{array}$ & $\begin{array}{c}1.059 \\
(0.963)\end{array}$ & $\begin{array}{c}2.230 \\
(0.0999)\end{array}$ & $\begin{array}{c}4.144 \\
(0.109)\end{array}$ & $\begin{array}{c}2.339 \\
(0.145)\end{array}$ \\
\hline$t=2005$ & $\begin{array}{c}6.693 \\
(0.766)\end{array}$ & $\begin{array}{c}13.71 \\
(0.984)\end{array}$ & $\begin{array}{c}9.768 \\
(1.604)\end{array}$ & $\begin{array}{c}1.805 \\
(0.166)\end{array}$ & $\begin{array}{c}3.154 \\
(0.181)\end{array}$ & $\begin{array}{c}3.248 \\
(0.242)\end{array}$ \\
\hline$t=2006$ & $\begin{array}{c}8.257 \\
(0.413)\end{array}$ & $\begin{array}{c}18.60 \\
(0.531)\end{array}$ & $\begin{array}{l}-1.830 \\
(0.865)\end{array}$ & $\begin{array}{c}2.779 \\
(0.0897)\end{array}$ & $\begin{array}{c}4.228 \\
(0.0975)\end{array}$ & $\begin{array}{c}1.781 \\
(0.130)\end{array}$ \\
\hline $\begin{array}{l}\text { Observations } \\
R^{2}\end{array}$ & $\begin{array}{c}12,214 \\
0.260\end{array}$ & $\begin{array}{c}12,214 \\
0.792\end{array}$ & $\begin{array}{c}12,214 \\
0.550\end{array}$ & $\begin{array}{c}12,214 \\
0.365\end{array}$ & $\begin{array}{c}12,214 \\
0.776\end{array}$ & $\begin{array}{c}12,214 \\
0.553\end{array}$ \\
\hline $\begin{array}{l}F \text {-value } \\
F \text {-test }\end{array}$ & $\begin{array}{c}214.3 \\
0\end{array}$ & $\begin{array}{c}2,326 \\
0\end{array}$ & $\begin{array}{c}745.2 \\
0\end{array}$ & $\begin{array}{c}350.6 \\
0\end{array}$ & $\begin{array}{c}2,115 \\
0\end{array}$ & $\begin{array}{c}755.6 \\
0\end{array}$ \\
\hline
\end{tabular}

Note: Standard errors in parentheses. 


\section{REFERENCES}

- Ackerberg, Daniel, Kevin Caves, and Garth Frazer. 2015. "Identification Properties of Recent Production Function Estimators." Econometrica 83 (6): 2411-51.

Ackerberg, Daniel, Gregory Crawford, and Jim Hahn. 2011. "Orthogonal Instruments: Estimating Price Elasticities in the Presence of Endogenous Product Characteristics." Unpublished.

- Berry, Steven T. 1994. "Estimating Discrete-Choice Models of Product Differentiation." RAND Journal of Economics 25 (2): 242-62.

Berry, Steven, James Levinsohn, and Ariel Pakes. 1995. "Automobile Prices in Market Equilibrium." Econometrica 63 (4): 841-90.

Berry, Steven T., and Ariel Pakes. 1993. "Some Applications and Limitations of Recent Advances in Empirical Industrial Organization: Merger Analysis.” American Economic Review 83 (2): 247-52.

-Berry, Steven T., and Joel Waldfogel. 2001. "Do Mergers Increase Product Variety? Evidence from Radio Broadcasting." Quarterly Journal of Economics 116 (3): 1009-25.

Byrne, David P. 2015. "Testing Models of Differentiated Products Markets: Consolidation in the Cable TV Industry." International Economic Review 56 (3): 805-50.

-Champsaur, Paul, and Jean-Charles Rochet. 1989. "Multiproduct Duopolists." Econometrica 57 (3): 533-57.

Chu, Chenghuan Sean. 2007. "The Effect of Satellite Entry on Product Quality for Cable.” PhD diss. Stanford University.

- Chu, Chenghuan Sean. 2010. "The Effect of Satellite Entry on Cable Television Prices and Product Quality." RAND Journal of Economics 41 (4): 730-64.

-Clerides, Sofronis K. 2002. "Book Value: Intertemporal Pricing and Quality Discrimination in the US Market for Books." International Journal of Industrial Organization 20 (10): 1385-408.

- Crawford, Gregory S. 2000. "The Impact of the 1992 Cable Act on Household Demand and Welfare." RAND Journal of Economics 31 (3): 422-49.

-Crawford, Gregory S. 2008. "The Discriminatory Incentives to Bundle in the Cable Television Industry." Quantitative Marketing and Economics 6 (1): 41-78.

-Crawford, Gregory S. 2012. "Endogenous Product Choice: A Progress Report." International Journal of Industrial Organization 30 (3): 315-20.

-Crawford, Gregory S., Robin S. Lee, Michael D. Whinston, and Ali Yurukoglu. 2018. "The Welfare Effects of Vertical Integration in Multichannel Television Markets." Econometrica 86 (3): 891-954.

Crawford, Gregory S., Oleksandr Shcherbakov, and Matthew Shum. 2019. "Quality Overprovision in Cable Television Markets: Dataset." American Economic Review. https://doi.org/10.1257/ aer.20151182.

Crawford, Gregory S., and Matthew Shum. 2007. "Monopoly Quality Degradation and Regulation in Cable Television." Journal of Law and Economics 50 (1): 181-219.

-Crawford, Gregory S., and Ali Yurukoglu. 2012. "The Welfare Effects of Bundling in Multichannel Television Markets." American Economic Review 102 (2): 643-85.

Draganska, Michaela, Michael Mazzeo, and Katja Seim. 2009. "Beyond Plain Vanilla: Modeling Joint Product Assortment and Pricing Decisions." Quantitative Marketing and Economics 7 (2): 105-46.

-Eizenberg, Alon. 2014. "Upstream Innovation and Product Variety in the US Home PC Market." Review of Economic Studies 81 (3): 1003-45.

Elhauge, Einer R. 2011. United States Antitrust Law and Economics. 2nd ed. St. Paul, MN: Foundation Press.

-Fan, Ying. 2013. "Ownership Consolidation and Product Characteristics: A Study of the US Daily Newspaper Market.” American Economic Review 103 (5): 1598-628.

-Gandhi, Amit, Luke Froeb, Steven Tschantz, and Gregory J. Werden. 2008. "Post-Merger Product Repositioning." Journal of Industrial Economics 56 (1): 49-67.

-Goolsbee, Austan, and Amil Petrin. 2004. "The Consumer Gains from Direct Broadcast Satellites and the Competition with Cable TV." Econometrica 72 (2): 351-81.

Hazlett, Thomas W., and Matthew L. Spitzer. 1997. Public Policy toward Cable Television: The Economics of Rate Controls. Cambridge, MA: MIT Press.

- Maskin, Eric, and John Riley. 1984. "Monopoly with Incomplete Information." RAND Journal of Economics 15 (2): 171-96.

McManus, Brian. 2007. "Nonlinear Pricing in an Oligopoly Market: The Case of Specialty Coffee." RAND Journal of Economics 38 (2): 512-32.

-Mussa, Michael, and Sherwin Rosen. 1978. "Monopoly and Product Quality." Journal of Economic Theory 18 (2): 301-17.

Nevo, Aviv. 2001. "Measuring Market Power in the Ready-to-Eat Cereal Industry." Econometrica 69 (2): $307-42$. 
Nosko, Chris. 2014. "Competition and Quality Choice in the CPU Market." Unpublished.

Olley, G. Steven, and Ariel Pakes. 1996. "The Dynamics of Productivity in the Telecommunications Equipment Industry." Econometrica 64 (6): 1263-97.

-Petrin, Amil. 2002. "Quantifying the Benefits of New Products: The Case of the Minivan." Journal of Political Economy 110 (4): 705-29.

-Shcherbakov, Oleksandr. 2016. "Measuring Consumer Switching Costs in the Television Industry." RAND Journal of Economics 47 (2): 366-93.

-Spence, A. Michael. 1975. "Monopoly, Quality, and Regulation." Bell Journal of Economics 6 (2): $417-29$.

-Sweeting, Andrew. 2010. "The Effects of Mergers on Product Positioning: Evidence from the Music Radio Industry.” RAND Journal of Economics 41 (2): 372-97.

-Sweeting, Andrew. 2013. "Dynamic Product Positioning in Differentiated Product Markets: The Effect of Fees for Musical Performance Rights on the Commercial Radio Industry." Econometrica 81 (5): $1763-803$.

US Department of Justice and the Federal Trade Commission (DOJ and FTC). 2010. Horizontal Merger Guidelines. Washington, DC: US Department of Justice and the Federal Trade Commission.

- Verboven, Frank. 2002. "Quality-Based Price Discrimination and Tax Incidence: Evidence from Gasoline and Diesel Cars.” RAND Journal of Economics 33 (2): 275-97. 